\title{
Review article: Towards resilient vital infrastructure systems - challenges, opportunities, and future research agenda
}

\author{
Seyedabdolhossein Mehvar ${ }^{1}$, Kathelijne Wijnberg ${ }^{1}$, Bas Borsje ${ }^{1}$, Norman Kerle ${ }^{2}$, Jan Maarten Schraagen ${ }^{3,4}$, \\ Joanne Vinke-de Kruijf ${ }^{1}$, Karst Geurs ${ }^{1}$, Andreas Hartmann ${ }^{1}$, Rick Hogeboom ${ }^{1,2,5}$, and Suzanne Hulscher ${ }^{1}$ \\ ${ }^{1}$ Department of Civil Engineering, Faculty of Engineering Technology, \\ University of Twente, 7500 AE Enschede, the Netherlands \\ ${ }^{2}$ Faculty of Geo-Information Science and Earth Observation, University of Twente, 7500 AE Enschede, the Netherlands \\ ${ }^{3}$ Faculty of Behavioral, Management and Social Sciences, University of Twente, 7500 AE Enschede, the Netherlands \\ ${ }^{4}$ TNO Defence, Safety and Security, 3769 ZG Soesterberg, the Netherlands \\ ${ }^{5}$ Water Footprint Network, 7500 AE Enschede, the Netherlands
}

Correspondence: Seyedabdolhossein Mehvar (a.mehvar@gmail.com)

Received: 17 January 2020 - Discussion started: 10 March 2020

Revised: 18 March 2021 - Accepted: 20 March 2021 - Published: 4 May 2021

\begin{abstract}
Infrastructure systems are inextricably tied to society by providing a variety of vital services. These systems play a fundamental role in reducing the vulnerability of communities and increasing their resilience to natural and human-induced hazards. While various definitions of resilience for infrastructure systems exist, analyzing the resilience of these systems within cross-sectoral and interdisciplinary perspectives remains limited and fragmented in research and practice. With the aim to assist researchers and practitioners in advancing understanding of resilience in designing infrastructure systems, this systematic literature review synthesizes and complements existing knowledge on designing resilient vital infrastructures by identifying (1) key conceptual tensions and challenges, (2) engineering and non-engineering measures, and (3) directions for future research. Here, a conceptual framework is developed in which infrastructures are defined as a conglomeration of interdependent social-ecological-technical systems. In addition, we define resilient infrastructures as systems with ability to (i) anticipate and absorb disturbances, (ii) adapt/transform in response to changes, (iii) recover, and (iv) learn from prior unforeseen events. Our results indicate that conceptual and practical challenges in designing resilient infrastructures continue to exist. Hence these systems are still being built without taking resilience explicitly into account. Our review of measures and recent applications shows that the available measures have not been widely applied in de-
\end{abstract}

signing resilient infrastructure systems. Key concerns to address are identified as (i) the integration of social, ecological, and technical resilience of infrastructure systems with explicit attention paid to cascading effects and dependencies across these complex systems and (ii) the development of new technologies to identify factors that create different recovery characteristics.

\section{Introduction}

Vital infrastructure systems (VIS) are considered to be the backbone of societies (Shrier et al., 2016). They deliver essential (vital) services in the areas of water, energy, transport, and telecommunication. Over time, these systems and their functioning have evolved into highly complex social, ecological, and technical systems. Analysis of these interlinked systems through the lens of resilience thinking has attracted increasing attention due to the high importance of these complex systems in providing vital services to societies that undergo change. Infrastructures are affected by disruptive shocks and long-term pressures while delivering services (Hallegatte et al., 2019). The likelihood that these systems fail by either natural or human-induced hazards is increasing worldwide as a result of global pressures such as urbanization (Wamsler, 2014), population growth, and an increase in the frequency and intensity of climate-driven haz- 
ards (Tsavdaroglou et al., 2018). Since infrastructures are highly interconnected and interdependent systems, any failure and disruption may quickly propagate through the network (Rinaldi et al., 2001; Bouchon, 2006; Field et al., 2012; Eidsvig and Tagg, 2015; Tsavdaroglou et al., 2018) and can have serious impacts on society and the economy (EC, 2004; Tsavdaroglou et al., 2018). In low- and middle-income countries, direct damage by natural hazards to infrastructure assets within transport and energy systems is estimated at about USD 18 billion per year (Koks et al., 2019; Nicolas et al., 2019). Given the high levels of economic damage and societal disruption of these shocks, it is widely acknowledged that urgent investments are required to design (more) resilient VIS (Meltzer, 2016; Brown et al., 2018; Meyer and Schwarze, 2019).

In recent resilience-related literature, more emphasis is laid on coupled socio-ecological and socio-technical systems (Galderisi, 2018). The generic and multidisciplinary nature of resilience has led to a wide variety of definitions and interpretations (Henry and Ramirez-Marquez, 2012; Meerow and Newell, 2015; Cimellaro et al., 2016; Hosseini et al., 2016; Ibanez et al., 2016; Connelly et al., 2017; Kurth et al., 2019; Patriarca et al., 2018; Xue et al., 2018; Hickford et al., 2018). For example, Henry and Ramirez-Marquez (2012) described system resilience as "how the system delivery function changes due to a disruptive event and how the system bounces back from such distress state into normalcy." Hosseini et al. (2016) stated that depending on which types of domain are considered (i.e., organizational, social, economic, and engineering), system resilience traditionally concentrates on the inherent ability of systems to absorb a disruptive effect on their performances, with more recent focuses on recovery aspects.

In the literature, there is also a classic distinction between "ecological resilience" and "engineering resilience" which was first made by Holling (1996), who identified a number of key differences between these two concepts. According to Holling (1996), engineering resilience concentrates on stability near an equilibrium steady state, in which resistance to disturbances and speed of return to the equilibrium are centered in this definition. In contrast, ecological resilience emphasizes conditions far from any equilibrium state in which a system can change into another regime of behavior due to instability.

More recently, Hickford et al. (2018) associated the resilience of (socio-ecological) systems with issues of security, emergency response, safety, and environmental and ecological aspects. Notably, there are similar terms/concepts used in resilience studies such as "resilience engineering" and engineering resilience. Resilience engineering focuses mainly on a system's ability to cope with performance variability (Hollnagel et al., 2006) and to bounce back to a steady state after a disturbance (Davoudi et al., 2012; Kim and Lim, 2016). In contrast, engineering resilience mainly refers to the tradi- tional view of system safety to withstand the failure possibility (Steen and Aven, 2011; Dekker et al., 2008).

Given the engineering nature of infrastructure systems and their capacity-oriented resilience definitions, in this paper, we adopt the concept of resilience engineering for designing infrastructure systems, by which we define resilient infrastructures as systems with ability to (i) anticipate and absorb disturbances, (ii) adapt/transform in response to changes, (iii) recover, and (iv) learn from prior unforeseen events.

The analysis of VIS from a resilience engineering perspective is an emerging discourse for both researchers and policy makers. Various studies were recently conducted to analyze the performance and reliability of different types of vital infrastructures such as transport and water systems (Frangopol and Bocchini, 2012; Guidotti et al., 2017; Gardoni, 2018). While the literature on resilience engineering has been burgeoning, existing literature focuses on defining and conceptualizing resilience and provides little guidance for designing resilient infrastructures. Yet, relatively few studies present actual assessments of infrastructure resilience (e.g., Donovan and Work, 2017; Panteli et al., 2017; Argyroudis et al., 2019). Moreover, these studies are fragmented from a research and practical perspective. As a result, the concept of resilience engineering remains difficult to apply when designing VIS.

To address this issue, we aim to provide researchers and other stakeholders with new insights into the key challenges, potential measures, and future research agenda for designing (more) resilient VIS. To achieve this aim, we conducted a systematic review of the literature and of recent examples of resilience engineering in practice. In doing so, we focused on the resilience of four infrastructure systems - transport, power, water, and telecommunication - since these four systems are recognized as the main infrastructures which provide vital services to humans.

\section{Method and materials}

To identify key challenges, opportunities, and research questions, a systematic review of the academic literature was carried out. We focused on how insights about resilience engineering are used for the design of VIS in four selected systems (transport, power, water, and telecommunication). This review was guided by the following questions: (1) what types of shocks and pressures affect infrastructures? (2) How is resilience engineering within VIS conceptualized? (3) What are the main conceptual tensions and challenges in design? (4) What are the key opportunities and measures for enhancing VIS resilience? (5) To what extent have existing measures already been applied, and what are recent developments and the best practices available? And (6) where is research in this field heading to, and what are important areas for future research? 


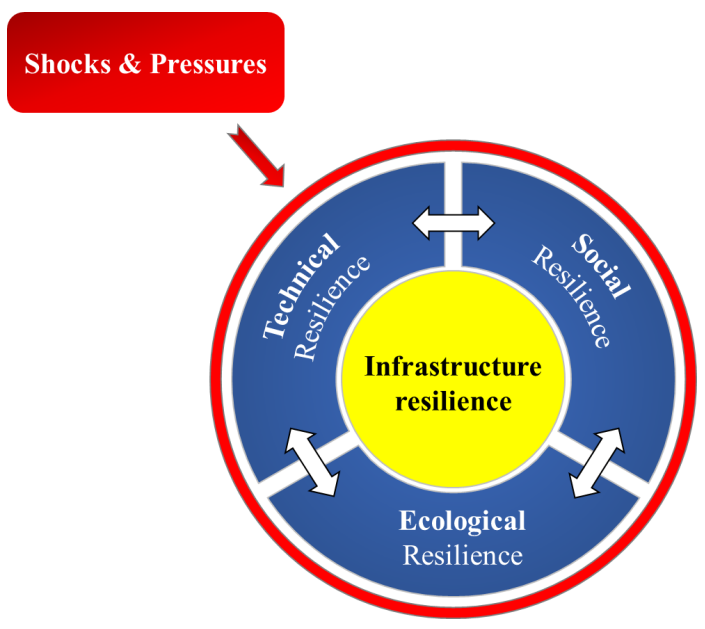

Figure 1. Conceptual framework showing that the resilience of infrastructure systems to shocks and pressures depends on the resilience of the interlinked social, ecological, and technical subsystems.

Elsevier's Scopus and Google Scholar citation databases were used to identify studies in which the concept of resilience engineering has been explored for the four selected infrastructure systems (i.e., water, energy, transportation, and telecommunication). Given the rapid development of the resilience concept, we limited our search criteria to four specific keywords (i.e., resilience engineering, critical infrastructure, vital infrastructure, and resilient infrastructure) with flexible combinations (e.g., resilience engineering AND vital infrastructure). Application of these criteria resulted in a selection of 160 studies, including books, full articles, and abstracts, in which the resilience of infrastructure systems was studied. Notably, the review was not bounded by a certain period or geography with the exception of our question about measures, developments, and best practices; to answer this question, we limited ourselves to recent literature (20122019).

\section{VIS design approaches and the resilience engineering concept}

In this article, we define VIS as a collection of interdependent social, ecological, and technical systems. Within this perspective, a conceptual framework is developed, indicating that resilience of the infrastructures to disturbances and trends depends on the resilience of each sub-system and their mutual interactions (see Fig. 1).

We further assert a cross-sectoral dependency between different types of VIS (see Fig. 2) in addition to the relations between the social-ecological-technical sub-systems (Fig. 1). This cross-sectoral relation refers to the mutual effects that function/malfunction of specific types of VIS may have on other types. Such a dependency is also called a "cascading

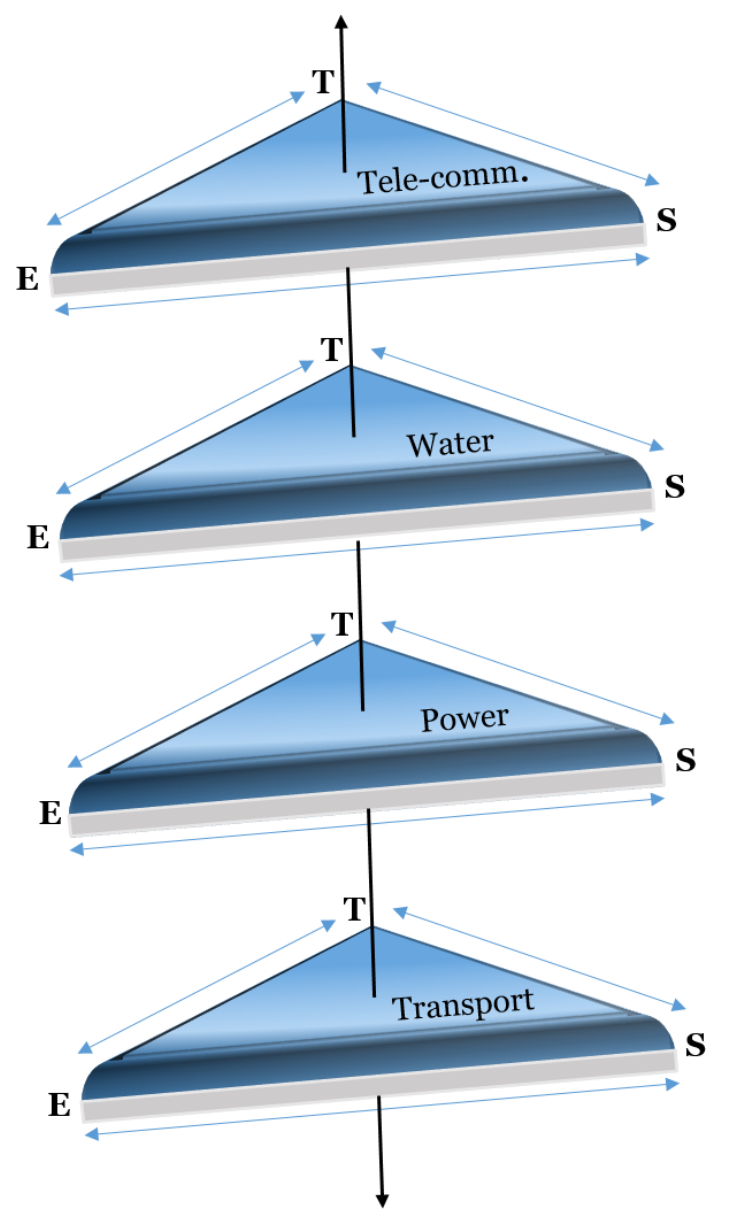

Figure 2. Schematic representation of different types of VIS, showing the cross-sectoral dependencies between the four types of infrastructures, as well as the interrelations within each system between technical (T), ecological (E), and social (S) sub-systems.

effect" of failure between infrastructures in different sectors. For example, power outage can considerably affect functioning of transport systems and other infrastructures, e.g., in the telecommunication sector. This interrelation is also seen in flood protection structures as any failure in these systems may result in severe damage to roads or any other types of infrastructure systems (more details on cascading effects of failure are provided in Sect. 4.2h).

The inter-/cross-sectoral dependencies considered within VIS here are in line with emerging approaches in analysis of VIS resilience such as "system-of-systems" perspectives. Such an integrated approach has been used in recent years to explore the relation between different components of an infrastructure system (e.g., user, physical asset, and network). Using these approaches can also help to explore propagation of failure across VIS in different sectors (more details of the system-of-systems approach are presented in Sect. 5.1.1a). 


\subsection{Shocks and pressures affecting infrastructure resilience}

Infrastructures are affected by many unexpected and sudden shocks, as well as by pressures caused by different natural or human-induced sources. In this article, shocks are understood as suddenly and instantaneously occurring disturbances, while pressures affect the system resilience in the long term (e.g., climate change, population growth). The long-term pressures are also called "stresses" in some studies (e.g., Bujones et al., 2013). Hallegatte et al. (2019) classified the causes (here, sources of disturbances) into four categories: (1) accidents as human-induced external shocks, (2) system failures due to any reason such as equipment failure, (3) attacks such as vandalism and cyber-attacks, and (4) natural hazards. Infrastructure resilience is also affected by global pressures such as urbanization, population growth, and climate change impacts, as well as by the growing tendency towards lack of underspending in upkeep and maintenance (mainly due to lack of funding at the level of the responsible government). The aforementioned causes can affect for instance transport systems in which accidents or any other human failures may lead to a disruption in road traffic or railway systems. In addition, cyber-physical systems (e.g., flood barriers, power plants, telecommunication systems), which are controlled and operated by high-tech technologies, can be disrupted by cyber-attacks and vandalism. Other examples of disturbances to infrastructures include failure of infrastructures due to a wide range of natural hazards (i.e., earthquakes and landslides, storms, and floods) that can affect for instance the energy industry by disconnecting the energy transformers in sub-stations. Such disturbances can be exacerbated within urban infrastructures due to high population density and considerable interconnection between infrastructures (Peters et al., 2004; McPhearson et al., 2015).

\subsection{Current approaches in designing VIS}

To better understand the design of resilient infrastructures, we consider it useful to distinguish between two approaches: (1) the performance-oriented approach and (2) the capacityoriented approach. Considering a wide range of contextspecific definitions for the two words "capacity" and "performance", here we define a system's capacity as its maximum capability and amount that a system (i.e., of VIS type) can contain to sustain its services and productivity. A system's performance refers to the execution of different actions by a system aiming to produce its services. Performancebased engineering is a widely explored discourse in the literature (see Anderies et al., 2007; Filiatrault and Sullivan, 2014; Spence and Kareem, 2014; Restemeyer et al., 2017) representing one of the approaches in designing infrastructures that has emerged from an architectural context (Oxman, 2008; Mosalam et al., 2018; Hickford et al., 2018). This approach is broadly applied at the design stage (Hick- ford et al., 2018) and is based on the capability of infrastructures to function and perform well in response to an expected pressure or disturbance. The performance-oriented approach, which is also referred to as the "control approach" (Hoekstra et al., 2018) or "robust control" (Anderies et al., 2007; Rodriguez et al., 2011), focuses on a system's performance to provide benefits for economic functions. More details on this approach and its application within infrastructure systems are beyond the scope of this study, since this review is grounded on the capacity-oriented approach as a different rationale in designing infrastructure systems.

A system's capacity refers here to its maximum capability and amount that a system (i.e., of VIS typ) can contain to sustain its services and productivity. A capacity-based approach focuses on a system's capacity to adjust its functioning prior to, during, or following changes and disturbances. This approach that has become the dominant discourse in the study of complex systems (Underwood and Waterson, 2013) refers to the resilience approach that examines the capability of systems to recognize and sustainably adapt to unexpected changes (Leveson et al., 2006; Madni and Jackson, 2009; Siegel and Schraagen, 2014; Woods, 2015). Therefore, in the resilience approach the focus is on maximizing the capacity of the system to be able to cope with, and adapt to, changes and disturbances (Berkes et al., 2003; Folke, 2006).

\subsection{Conceptualization of resilience engineering within VIS}

Reviewing the literature shows that the emerging concept of resilience engineering within infrastructures (originating from the capacity-oriented approach) is one of the main concerns in managing these systems (LRF, 2014, 2015) in which complex mechanisms are involved for planning, financing, designing, and operating systems (Hickford et al., 2018). There are a wide range of definitions available in the recent literature for the concept of resilience engineering (e.g., Woods, 2015; Sharma et al., 2017; Hollnagel, 2017; Hickford et al., 2018; Gardoni and Murphy, 2018; Bene and Doyen, 2018). According to Hickford et al. (2018), while some definitions have focused on the ability of the organizations to anticipate the threat and rapidly recover (e.g., Hale and Heijer, 2006), some other studies define resilience engineering as the ability of the socio-ecological system to absorb changes and still keep the same function (e.g., Meerow et al., 2016).

Many studies have been conducted to assess resilience of infrastructure systems either as socio-ecological systems (Fischer et al., 2015; Muneepeerakul and Anderies, 2017; Walker et al., 2018) or as socio-technical systems (Bolton and Foxon, 2015; Eisenberg et al., 2017). Within the "sociotechnical" approach, Salinas Rodriguez et al. (2014) stated that resilience of the flood protection structures depends on how human actors play a role in managing and adapting physical components of the system such as the structure of dikes or embankments. Thus, resilience of the flood protec- 
tion system relies on the degree to which the system is able to be self-organizing (social resilience) and is capable of increasing its capacity for adapting to changes. Notably, within the social resilience perspective, sustainable governance of the infrastructure systems through either adaptive or transformative approaches plays a pivotal role in enhancing the system's resilience. More details of these two approaches are provided in Sects. 4 and 5.

In addition to interaction between social and technical systems, there is also an interplay between physical and ecological systems. From a "technical-ecological" perspective, infrastructure systems encompass the surrounding built environment (Wolch et al., 2014), and therefore a physical system's resilience is also related to the natural system's resilience. Such an interaction with nature highlights the degree to which natural assets (e.g., wetlands ecosystems such as mangroves and urban green areas) can increase the capacity of the whole system to cope with shocks and stresses (ecological resilience). Social and ecological systems are also interlinked systems (Adger, 2000). Ecosystems as natural resources, also referred to as "natural infrastructures", provide a variety of services and goods (e.g., flood protection, food provision) that directly or indirectly contribute to human well-being (Mehvar et al., 2019a, b) and, therefore, contribute to the resilience of societies (referring to the "socioecological" perspective).

In this article, we define resilience engineering in line with previous studies (i.e., Woods, 2015; Hollnagel, 2011, 2017; Connelly et al., 2017; Hickford et al., 2018), as we distinguish between five principles that are commonly shared within most definitions. These principles relate resilience engineering to the ability of the system to (1) anticipate, (2) absorb, (3) adapt/transform, (4) recover, and (5) learn from prior unforeseen events. These five principles are translated into a definition of resilience engineering in the context of VIS as the system's ability to (i) monitor for and anticipate shocks and pressures, (ii) function at thresholds of service delivery, (iii) cope with unexpected changes by its either adaptive or transformative capacity, (iv) either return to its normal (steady) condition or re-organize after a disruption has occurred, and (v) learn from what has happened to improve system behavior in facing future unforeseen events. Notably, applying the resilience engineering concept for designing VIS here does not mean "engineering" the social and ecological sub-systems; therefore, the socio-ecological aspects are not considered separately from the technical aspects. This implies that VIS are integrated social-ecological-technical systems, and consequently the performance of each sub-system can affect the other sub-systems. Thus, this perspective differs from the engineering perspective in which infrastructures are first and foremost defined as technical systems.

\section{Identifying main challenges in designing resilient VIS}

In this section, the main challenges related to the design of resilient VIS are identified and divided into two categories: (1) conceptual tensions and (2) challenges in the fields of application. This sub-division is considered here to better understand and distinguish what the different types of current challenges and limitations in designing VIS are, arising from the concept of resilience engineering, as well as the applications in which this concept is applied.

\subsection{Conceptual tensions}

In designing resilient infrastructure systems, designers are faced with a number of conceptual tensions that arise from the multidisciplinary nature of the resilience engineering concept. In this article, we identify and distinguish these challenges and associated ongoing debates in resilience literature as they are briefly described below.

\section{(a) Bouncing back versus bouncing forward}

Within the various academic communities, the resilience concept is perceived both positively and neutrally/negatively (Brown et al., 2012; McEvoy et al., 2013; Meerow et al., 2016; Sharma et al., 2017). According to Meerow et al. (2016), the different connotations are due to the evolution of the resilience concept, in which resilience is represented as a characteristic of a system that can be positive, negative, or framed in a normative fashion (Cote and Nightingale, 2011). Desirability or non-desirability of the resilience concept is dependent on the question of resilience of what, to what, and for whom (EC, 2015). For example, Meerow et al. (2016) indicated that within the equilibrium-focused approach, resilience is perceived as the ability of a system to return to its normal (steady) condition after a disturbance (Coaffee, 2013), representing the resilience concept positively (assuming that the normal condition of the system is steady and desirable). However, a system can be resilient yet undesirable (Scheffer et al., 2001; Gunderson and Holling, 2002; Wu and Wu, 2013).

Within such different interpretations, there is also a challenge arising from the resilience engineering concept which is related to the idea of bouncing back (returning to the predisaster state). This is in contradiction with the sometimesstated goal of promoting justice among societies (Nagenborg, 2019). According to Nagenborg (2019), understanding resilience and the recovery process as a window of opportunity (bouncing forward) would promote justice. Of particular relevance here is that poor communities are more vulnerable to shocks and therefore likely to be less resilient. However, there are cases such as slum areas in which communities have very strong social networks and ties that increase the resilience of these groups. Yet, calling communities or individuals "resilient" may be an excuse for not changing any- 
thing in the environment. In such a context, which emphasizes the social resilience of VIS, resilience can become a concept that promotes conservative, bouncing-back-oriented policies (maintaining the status quo being the epitome of conservatism).

\section{(b) Resilient versus robust systems}

Within the infrastructure systems, robustness refers to the ability of a system to remain functioning under variable magnitudes of disruptions and pressures (Mens et al., 2011). Thus, it refers to the tolerance capacity of the system (Ganjurjav et al., 2019) and persistence characteristic of the system reflecting the engineering principle of resistance to disturbances (Chelleri, 2012). Notably, robustness and resilience are related characteristics if infrastructure performance continues its functioning after a disruption (Anderies et al., 2013; Meerow et al., 2016).

From a different perspective, robustness (referring to resistance capacity) may not be interpreted and equated with resilience. Martinez et al. (2017) point out that resistance is the ability of systems to withstand a pressure without modification, while resilience is the ability of adapting to disturbances and returning to the original status. In line with this definition, Hoekstra et al. (2018) stated that robustness is a characteristic of the control approach that aims to increase safety of the system by resisting changes and eliminating risks; therefore, it contradicts the resilience approach which refers to responding (adapting) to unexpected changes. Markolf et al. (2018) state that the effectiveness of the robustness (also named control) approach can be reduced due to current infrastructure-related challenges and pressures such as climate variability and unpredictability, as well as interdependency between the systems. Another reason why robustness cannot be equated with resilience is that robustness only works in situations where disturbances are wellmodeled, whereas resilience applies to a set of disturbances that are not well-modeled and that change (Woods, 2015).

\section{(c) Adaptive versus transformative capacity}

There are different governance strategies embedded in the resilience concept. Some studies define resilience as the adaptive capacity of a system (Batty, 2008), referring to the flexibility of the system to allow changes while controlling disruptions (Hoekstra et al., 2018). Similarly, Woods (2015) and Clark et al. (2018) point out that extensibility or the adaptive capacity of a system is of importance in maintaining functionality when faced with unexpected changes. According to Chaffin et al. (2016), while adaptive governance aims to build resilience through adaptive management in a desirable system regime, transformative governance aims to shift the system to an alternative and desirable structure. Notably, the transformative capacity of a system can be considered on different scales, ranging from personal to organiza- tional (O'Brien, 2012; Chaffin et al., 2016). Despite the separate nature of these two approaches mentioned above, McPhearson et al. (2015) referred to other studies conducted by Holling (2001), Walker et al. (2004), and Biggs et al. (2012) in which resilience was defined as a multidisciplinary concept including both adaptive and transformative capacities of a system.

\section{(d) Temporal and spatial scales}

In designing infrastructure systems, one of the challenging issues is to determine a proper timescale of action in the face of disturbances. The question is whether the focus should be on short-term and rapidly occurring disasters (hurricanes) or more on gradual changes such as climate-change-induced hazards (Wardekker et al., 2010; Meerow et al., 2016). However, Pearson et al. (2018) pointed out that designing infrastructures within resilience thinking needs to evolve faster than the actual demand for services, since the timescale of the system realization is comparable with changes in environmental scenarios and, therefore, does not allow for a quick response. There is also an issue of determining the spatial boundary while incorporating the resilience concept into designing infrastructure systems. This highlights the question of "resilience for where", referring to the boundary of the system in which there might be a complex set of networks connected on different spatial scales (Meerow et al., 2016).

\section{(e) Unit of analysis}

Depending on the extent of the services provided by an infrastructure system, analyzing a system's resilience can be performed, for example, for an individual (person), team, organization (e.g., company), or society as a whole. Notably, the complexity level increases from a lower (i.e., individual) to a higher (i.e., society) level, and the main challenge is how to connect these levels within a resilient system, given that a system is constrained by a level above and below. The target unit of analysis can and perhaps should be considered when designing the system or analyzing the resilience of an infrastructure system.

\section{(f) Risk versus resilience}

Risk is widely defined within the literature as a combination of the occurrence of a disturbance and the exposure and vulnerability of a system within different contexts (e.g., Ness et al., 2007; Covello and Merkhoher, 2013; Oppenheimer et al., 2014). In this article, the concept of risk is defined as the probability of occurrence of a disturbance (hazard) to VIS times the consequences (damage) to the systems.

In general, risk and resilience concepts are viewed differently. One may consider resilience a distinct concept from the traditional risk management approach that is used to mitigate or even avoid likely risks. Within this perspective, in resilience engineering, the aim is to become less risk-averse, 
implying that a certain level of risk is accepted; however, the big question is, what is the acceptable risk? By some accounts, resilience engineering is considered a related concept to risk management, reflecting the idea that if there is no risk, there is no need to be resilient. Resilience is a function of the present hazard type(s) and its magnitude (which it has in common with risk). Within this perspective, risk assessment including risk identification, prioritization, and mitigation processes is a basis for designing resilient infrastructure systems, representing risk as an exponent of resilience. However, with respect to the risk- and resilience-related studies, there is a shift in some terminologies used. For example, in the current literature, the term "resilience" sounds more positive than the traditional term "fault tolerance".

From a risk assessment perspective, a key question is whether priority should be given to reducing hazard consequences or risks. This dilemma is particularly relevant for infrastructures that aim to protect people against natural hazards. For example, investments in flood protection structures (e.g., dikes, seawalls) in vulnerable coastal areas may help to reduce risks (by reducing hazard impacts), via raising embankment heights, which can reduce the flood frequency. However, protective measures may also be counterproductive since they may encourage people to move and live closer to the sea, increase economic development, and thus increase potential consequences (damage) and exposure areas to flooding, which will result in increasing the risk. Such risks can potentially be reduced by increasing flood risk awareness among coastal communities through, for instance, personal experience, risk communication, and financial insurance (Filatova et al., 2011). In addition, society's attitude towards risk is not well included in current decisionmaking strategies, given that the concept of risk that is currently accepted by people may potentially change rapidly. De Koning et al. (2019) conducted a study on behavioral motives of property buyers and sellers in eight coastal states in the USA, showing that households' choices to retreat from flood zones are dependent on two factors: information that stimulates their feeling of fear and hazardous events.

\subsection{Challenges related to the application of resilience engineering}

Apart from the literature-based tensions regarding the design of resilient VIS, there are also limitations and barriers in practice. We identify these application-based challenges as they are explored and discussed below.

\section{(g) Data scarcity}

Appropriate data are a necessity to design and manage resilient infrastructures. For example, strengthening infrastructures against natural hazards is pragmatic if there are appropriate data on the spatial distribution of extreme events (Hallegatte et al., 2019). However, there are many uncertainties in predicting the impacts of extreme events and climate change impacts on infrastructures. Troccoli et al. (2014) stated that the limits between resistance and resilience of the current infrastructures are determined based on the prior climate data; thus there is a need to redefine these limits by understanding the current meteorological variables under climate change. Majithia (2014) conducted a study highlighting the information gap in analysis of future climate-driven changes relevant to the energy industry. According to Majithia (2014), there are no data on future changes in wind frequency and intensity, nor are there data for probabilistic projection of wind speed and frequency and intensity of lighting, snow, etc. This lack of information is also seen among disaster response organizations, resulting in insufficient data exchange and poor performance in responding to the occurrence of a disaster. In particular, such an absence in data is problematic when there is a failure in the communication system, preventing organizations from an effective response and relief operation (Shittu et al., 2018). These uncertainties are extended to other long-term pressures such as urbanization and population growth, making it difficult to forecast the future demand for infrastructure services.

\section{(h) Predicting cascading effects of failure}

Infrastructures are highly networked and interconnected systems (Markolf et al., 2018) with cascading effects of failures within different systems, implying that a disruptive event in one infrastructure can lead to further consequences in other infrastructures (Birkmann et al., 2017; Hickford et al., 2018). According to Markolf et al. (2018), this interconnection can be either physical (output of one system is the input required for other systems, such as electricity needed for transportation and water-related infrastructures) or geographical, referring to a shared common location for a set of infrastructure systems (e.g., underground pipelines and electric transmission cables). Capturing the dependencies among infrastructure systems is needed for analyzing functionality of the systems and identifying the hazard impacts on different system components. Understanding the interdependency between VIS can also help to develop recovery measures (Gardoni, 2018), an aspect which has not been well included in current design and decision-making procedures. Lack of sufficient data on cascading effects has resulted in assuming that these effects grow linearly between different types of infrastructures, while in reality this evolution may not be similar for all the interconnections (Tsavdaroglou et al., 2018). Notably, such cascading effects of failures not only are cross sectoral but also can occur within a particular sector. For example, in transport systems, failure in one mode of transport may considerably affect resilience of the other modes. 


\section{(i) Challenges with new technology/initiatives}

The incorporation of new technologies and innovative solutions into designing infrastructures may contribute to a better understanding of the interconnections among different vital infrastructures, promoting resilience at the time of shocks and disruptions. However, this is not always the case; new technologies may also increase interdependency between infrastructures (Birkmann et al., 2017; Hickford et al., 2018), leading to considerable service interruptions (e.g., high dependency of energy and transport systems on information technology). Designing infrastructure systems with much reliance on technological advances may result in overestimation of the protection level and under-estimation of the variability in the system in response to changes, causing over-confidence in the robustness of systems (Markolf et al., 2018). Therefore, there might be a case that no expert can immediately respond to the failures because of too much reliability on digital technology, and this may eventually lead to a decrease in system resilience.

There might also be controversies within social and technical aspects. For example, in the "smart city" initiative which is designed to increase the security of urban areas, it is proposed to install security cameras. But this proposal has its own disadvantages, since such a monitoring system affects people's privacy as they are continuously traced. Therefore, equipping new infrastructures with such tools may, on the one hand, create extra functionality but, on the other hand, cause controversies. Such debates are also seen in designing flood protection structures in which, for example, a seawall may block the ocean view and cause damage to coastal ecosystems, becoming a source of conflict between coastal zone managers, ecologists, and tourists.

\section{(j) Quantification of resilience}

Quantifying resilience of the infrastructure systems is a challenging issue (De Regt et al., 2016). Knowing the infrastructure's resilience in quantitative metrics (e.g., recovery speed) can facilitate disaster risk assessment and decisionmaking procedures in the sustainable management of these systems. However, because of the difficulty in quantifying resilience-related metrics, decision makers face a challenge to either take decisions or evaluate alternatives in resilience enhancement plans. Hence, they may become reluctant to take resilience into account in their decision-making processes. Hickford et al. (2018) pointed out that different approaches including probabilistic graph theory and analytical methods have been used to measure a system's resilience (see for example Ibanez et al., 2016; Zimmerman et al., 2016; Nan and Sansavini, 2017; Ouyang, 2017; Zhang et al., 2018). A variety of metrics are identified and applied to a range of quantifiable impacts depending on disruptive effects and resulting losses of functionality of the infrastructures (Hickford et al., 2018).

\section{(k) Multi-functionality of infrastructures}

Multi-functionality of the infrastructure systems may increase or decrease the resilience of the system. On the one hand, multi-functionality may decrease resilience of a system, since this characteristic may decrease the adaptability of the system to changes because of the difficulty for some functions to change in the long run. For example, with respect to flood protection structures, repairing, reconstructing, and raising dikes may decrease the system's resilience. On the other hand, if an infrastructure system still provides multiple functions after a failure/damage occurs but different ones than initially aimed for, this system still represents an example of a resilient infrastructure, since it adapted to changes while providing different functions. For instance, closure dikes in the Netherlands initially aimed at poldering to create farming area; however the structure led to protection against floods, as well as fast road transport connecting the North Holland and Friesland provinces. Therefore, there might be some resilience hidden anyhow in constructing the infrastructures, since the system might be more resilient in the future than it was initially considered to be. The Multifunctional Flood Defences program (MFFD) is another good example emphasizing multi-functionality of infrastructures in the water sector in the Netherlands which focuses on the interplay between the primary function of flood defenses and other societal needs such as housing, renewable energy, and recreation (Kothuis and Kok, 2017).

\section{(l) Long timescales}

From a recovery perspective, enhancing resilience of infrastructure systems is often a long procedure including (1) analyzing the situation after a disaster/shock, (2) drawing lessons from the analysis, (3) turning the lessons into planning and policy making, and (4) implementing the plans. For instance, the Sendai Framework for Disaster Risk Reduction (SFDRR) is an example of wide-reaching policy frameworks for a period of 15 years (2015-2030). This framework aims to integrate disaster risk reduction plans within different sectors including health, which requires integrative collaborations across local, national, regional, and international levels (Aitsi-Selmi et al., 2015). In many cases there is no time to wait for recovery plans. For example, poor communities in developing countries cannot wait for years to have a master plan. This dilemma typically results in re-building the houses and lives (by local communities) in a similar way to how they were built before the disaster occurred. This results in retaining the same level of vulnerability and being (again) less resilient to future shocks/hazards, representing an example in which resilience as "bouncing back to an initial state" is clearly undesirable. Therefore, the long timescale of resilience enhancement schemes should be considered when planning measures. Hence, being pro-active is a better strategy than being reactive. 


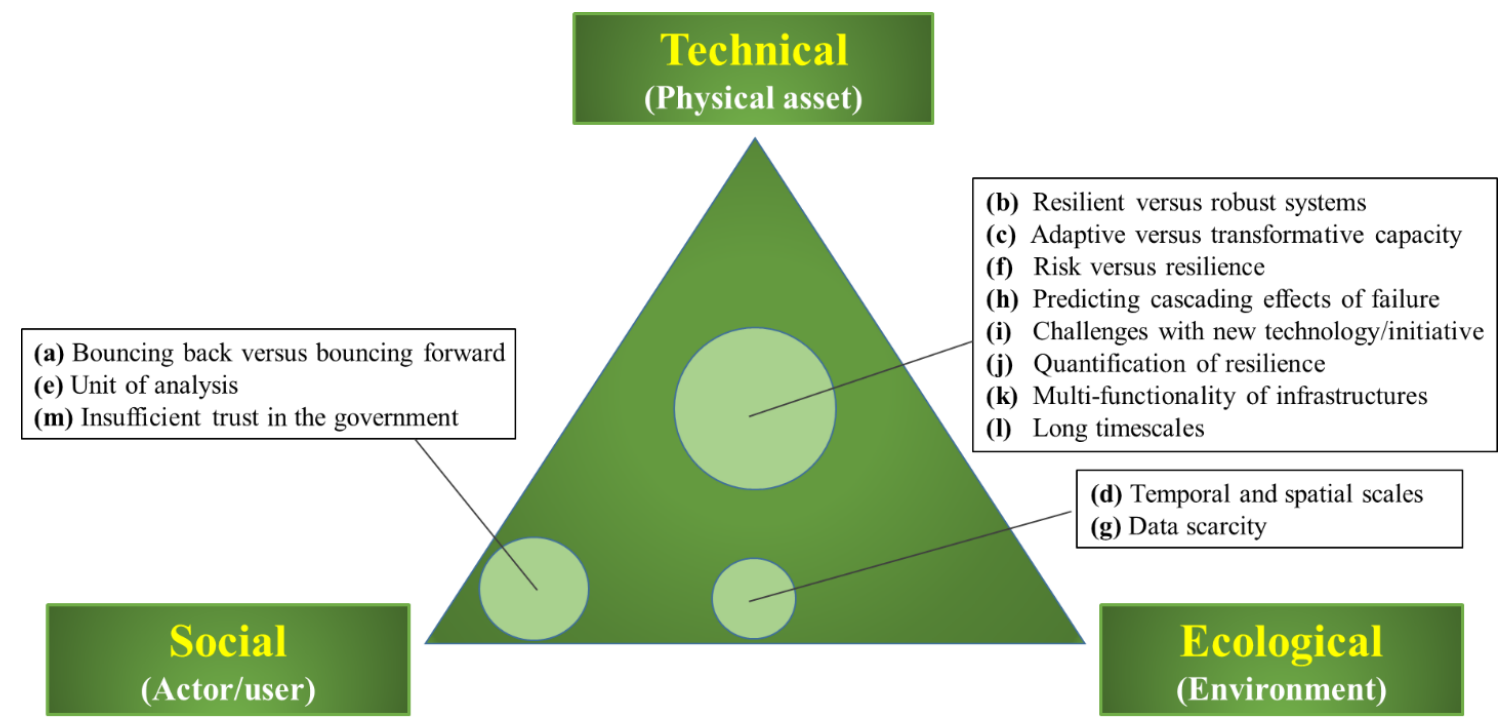

Figure 3. Conceptual and practical challenges in designing resilient vital infrastructures and their relevance to the system's components.

\section{(m) Insufficient trust in the government}

Trust between stakeholders plays a key role in the success of collaborative decision-making procedures, for instance, in the context of the resilience of natural resource management institutions (Stern and Baird, 2015). For different reasons, there might be communities that do not fully trust their government to implement the recovery processes. This lack of trust is especially seen within communities that are likely to suffer the most from disasters, and they often do not receive enough support from the government. Conversely, high levels of faith and trust from societies in the government can result in a better recovery plan. This can be seen by, for example, an immediate evacuation by the residents of an exposed area to a disaster when an early public alert is announced by the government. For instance, in terms of preparedness for natural hazards and controlling disturbances, Wei et al. (2019) found that households in Taiwan with a higher degree of trust in the government and authorities are more likely to accept preparedness activities.

\section{Other limitations}

In addition to the challenges highlighted above there are other limitations in designing resilient infrastructures. These limitations include (1) discontinuity between technical, ecological, and social disciplines (Ahlborg et al., 2019); (2) changes in government, which often lead to change in policies, plans, and infrastructure design; (3) lack of proper coordination for governance of infrastructures and less opportunity for benchmarking and practice-based learning due to the absence of large-scale implementations of resilience approaches (Hickford et al., 2018); and (4) macro-economic unforeseen situations caused by, for example, Brexit or the
COVID-19 virus pandemic which do not affect the infrastructures directly but still may reduce their resilience due to their overuse or lack of maintenance and reduction in maintenance budget, etc. It should also be noted that recovery of infrastructure or considering adaptive alternatives at the time of a disaster is not often feasible in practice. For example, in designing flood protection structures, the adaptive alternatives/options addressed in the design manuals are often costly, leading to excluding these options from being implemented in reality.

\subsection{Relevance of the challenges to the VIS components}

The conceptual design and practical challenges mentioned in Sect. 4.1 and 4.2 are rooted in different components of infrastructure systems, including physical asset, environment, and actor/user, referring to the technical, ecological, and social components, respectively (i.e., sub-systems in Fig. 1). Figure 3 illustrates the relation of these challenges to each other within these components. This relation is shown through positioning these challenges in the figure depending on whether the challenge arises mostly from a particular component or whether it is related to two/three components. In particular, physical asset here refers to the physical and technical characteristics of the system, environment refers to the natural settings and surroundings of the system in which it functions and provides services, and actors/users refers to the policy makers (e.g., government) and users of the infrastructure services (i.e., citizens). Figure 3 shows that most of the challenges pertain (roughly) equally to the integration of the three components, while some of them arise mostly from the actors/users of the systems (e.g., units of analysis) or from coupled interconnections between asset/environment and actor/user (e.g., predicting long-term pressures). 

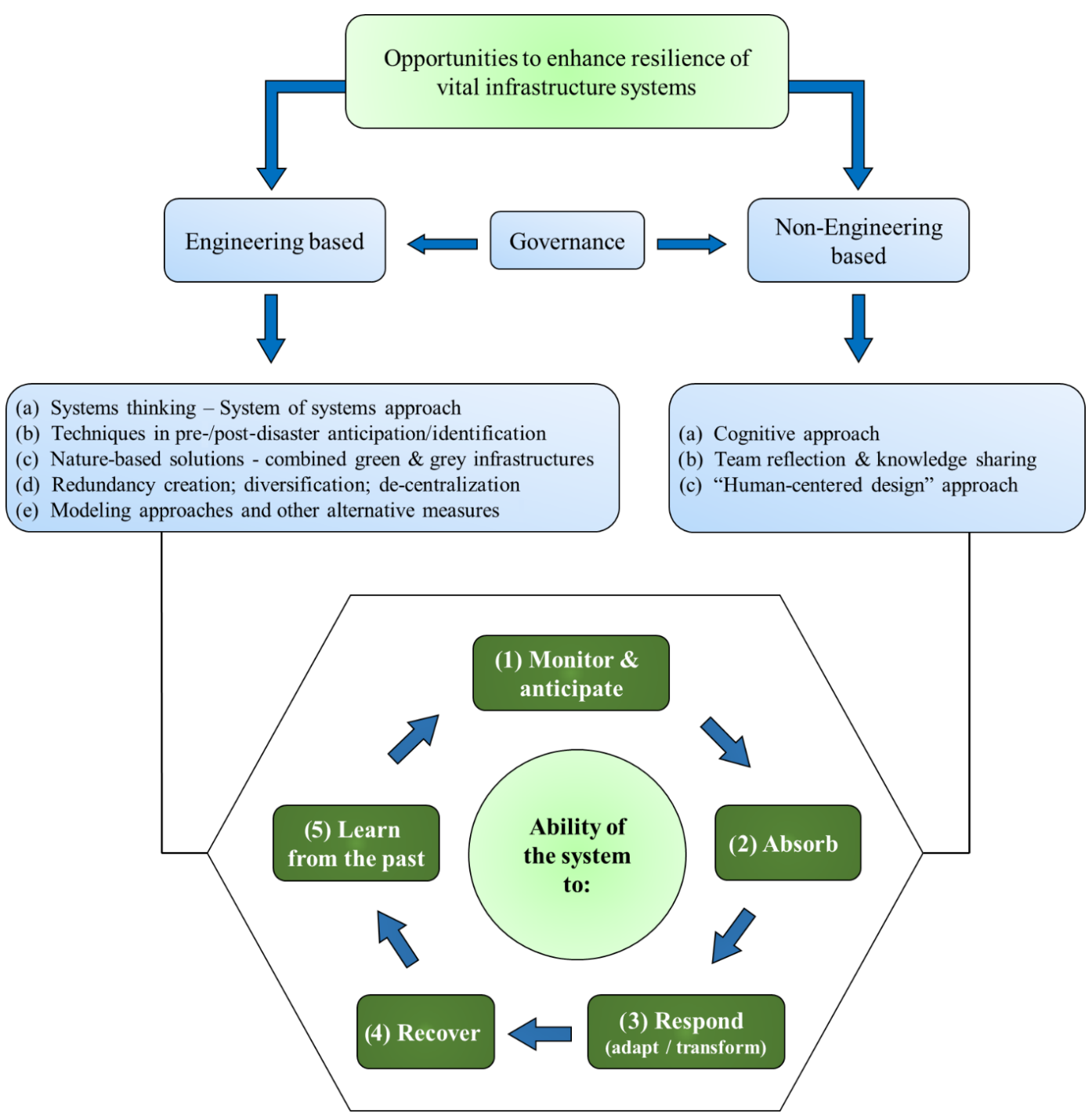

Figure 4. Main engineering-based and non-engineering-based opportunities and measures to improve the five main system capabilities required for a resilient vital infrastructure.

\section{Towards resilient VIS}

\subsection{Opportunities and measures to enhance resilience}

In this section, potential opportunities and measures to enhance resilience of VIS are identified. We divided these measures into two categories - (1) engineering and (2) nonengineering - given that proper governance plays a key role in parallel to these measures to ensure that infrastructure services are constantly available to users. Figure 4 shows these opportunities and their linkage to the five main system capabilities required for resilient VIS as previously mentioned in Sect. 3.3.

\subsubsection{Engineering-based measures}

\section{(a) Systems thinking - system-of-systems approach}

In order to improve infrastructure resilience, a whole system view is required which includes the physical assets, users, and stakeholders (Pearson et al., 2018). Therefore, there should be a holistic approach focusing on the ways that the system's constituent parts interrelate and work over time within larger systems. Infrastructure resilience might be neglected or sacrificed among the users due to lack of having a systems view, which may highlight more immediately recognizable system properties such as sustainability or productivity (Meadows, 2008). Analysis of the infrastructures through a lens of systems thinking provides a better insight into understanding the system's complexity and interconnectivity 
which is required to enhance its resilience comprehensively and coherently (Field and Look, 2018). This approach can improve the infrastructure system's ability in terms of better anticipating, absorbing, responding, and recovering from changes by disruptive events.

The systems-thinking perspective is similarly represented by the system-of-systems approach which describes the infrastructure systems and multiple interconnections among different operational scales, from both the demand and the supply sides (Thacker et al., 2017). Within the system-ofsystems perspective, there are different levels of representation in a multi-scale structure. Thacker et al. (2017) defined these levels as (1) customers or consumers, who receive the infrastructure services (the lowest level from the demand side); (2) physical asset performing a specific function (the lowest level from the supply side); (3) sub-system representing different networks within a particular infrastructure system that fulfill a specific function; (4) system as a collection of sub-systems presenting a set of connected assets with a collective function in order to facilitate flow of the services to the customers; (5) system of systems as the top level which refers to the interconnected systems in different sectors.

\section{(b) Emerging techniques in pre-/post-disaster anticipation/identification}

With respect to the pre-disaster anticipation and preparedness for potential hazards, early warning systems play a pivotal role in raising social awareness, quick evacuation, and much lower social disruptions after a disaster occurs. Remote sensing-based methods that support every aspect of risk assessment, routine surveillance, early warning, and event monitoring have also been developed (Kerle, 2015). In terms of post-disaster recovery, automatic and accurate damage identification can be performed by first obtaining actionable, accurate, and timely disaster data/information, which is a necessity at the time of disaster. The term "timely" depends on the location and type of devastating event and can be interpreted on different timescales (e.g., in the case of an earthquake in Japan, there are hourly data/information updates). The required data can also be obtained by using spaceborne remote sensing, providing satellite images that serve as a basis for an inventory to show the extent of the affected area and critical hotspots. However, in particular, satellite images have been shown to have severe limitations in damage mapping (Kerle, 2010), mainly due to their comparatively limited spatial detail (resolution is at best $30 \mathrm{~cm}$ for commercial imagery) but also due to their vertical perspective that severely limits the damage evidence that can be detected. Damage data can also be provided by drones, which yield more local observations that can be incorporated further into 3D modeling of the areas (Nex et al., 2019; Kerle et al., 2019a, b). In particular, advances in machine learning have led to methods for accurate damage identification from drone data (Nex et al., 2019; Kerle et al., 2019a). Using remote sensing tech- niques, the system's recovery can be detected in terms of (1) physical reconstruction and (2) residual functionality of the infrastructure.

Remote sensing data have also been used to assess postdisaster physical and functional recovery, which has been considered a proxy for resilience. Sheykhmousa et al. (2019) used multi-temporal satellite images to assess recovery via a quantification of land-cover and land-use classes following the 2013 Typhoon Haiyan in the Philippines, identifying spatially highly variable recovery patterns. However, the imagebased approach relies on accurate identification of damage as the benchmark against which recovery is measured. Since much of the Haiyan damage was actually caused by a storm surge that littered vast areas with a blanket of debris and rubble, this assessment was error-prone (Ghaffarian and Kerle, 2019; Ghaffarian et al., 2019). A later correlation of observed recovery with detailed field data from about 6000 household interviews also raised doubts about the common assumption that a resilient community will recover the quickest (Kerle et al., 2019b). Remote sensing data have also been shown to be useful in updating databases of buildings and other infrastructure after a disaster (Ghaffarian et al., 2019), which is useful to recalculate the changed risk.

\section{(c) Nature-based solutions - combined green and grey infrastructures}

Infrastructure systems are categorized into two different types: (1) grey infrastructure and (2) green infrastructure. Grey infrastructure refers to the traditional (hard) engineering systems that are often built from steel or concrete, such as those in water management and flood protection systems (e.g., seawalls, break waters, pipes, pumps). Green infrastructure is the natural and semi-natural system that is designed and managed to provide ecosystem services to people (EC, 2013), infrastructure such as mangroves, coastal dunes, storm water ponds, green roofs, and urban forest. Green infrastructure thus plays an important role in enhancing the resilience of the system, through for instance, limiting extreme temperatures in urban areas or increasing the capability of the coastal communities to withstand sea level rise through adaptive coastal ecosystems (EC, 2015). Grey infrastructure has little flexibility to adapt to changes or to transform to a new structure following a disruptive event. Depending on the function and importance, both grey and green solutions are often dimensioned based on risk-based cost-benefit analysis, which means that in principle their cost is optimal with respect to their benefits. Nature-based solutions either by themselves or combined with grey infrastructures can provide a more sustained opportunity to increase resilience of the infrastructures (Browder et al., 2019; Hallegatte et al., 2019).

Within the green-infrastructure systems, the concept of building with nature (nature-based solutions) has been developed to utilize natural processes, providing opportunity for the natural environment as part of the infrastructure de- 
velopment process (De Vriend and Van Koningsveld, 2012). Such nature-based solutions may involve restoration plans of degraded ecosystem services (Sapkota et al., 2018; Mostert et al., 2018) and also enhancement of healthy ecosystem services, such as supporting the natural storm recovery potential of dunes that function as flood protection (Keijsers et al., 2015). Nature-based solutions can be functional by themselves or can be developed to improve the performance of grey infrastructure (WWAP, 2018).

As an example, the Sand Motor mega-nourishment (Stive et al., 2013; De Schipper et al., 2016), located near the most densely populated region in the Netherlands is an innovative way to promote resilience of the coastal communities to climate-change-driven hazards, by not only increasing the area available for recreation and creating new opportunities for the beach tourism industry but also improving coastal safety in the long term due to increased dune growth. Such a solution improves the system's ability to absorb storm events, as wider beaches dissipate more wave energy, hence reducing erosion of the dunes (natural flood defense) and supporting recovery of the dunes by windblown sand transport (Galiforni Silva et al., 2019). At a longer timescale it allows the flood defense system to flexibly adapt to changes in rates of sea level rise.

"Room for rivers" (Klijn et al., 2018) represents another form of "building with nature" suggesting to lower and broaden the flood plain and create river diversions, widen the conveyance channels, and provide temporary water storage areas, so there would be more room for embanked river systems to absorb high-discharge events. Regarding the flood defense structures themselves, the emerging concept of "tough dikes" in the Netherlands, which would keep their functionality if parts of the structure were breached due to extreme events, can also be considered an example of resilient flood defenses. This type of dike that has residual strength after the occurrence of a failure prevents the failure from quickly propagating throughout the whole structure. As a result, a longer time is available for damage recovery, thus promoting resilience of the system against unforeseen hazards.

"Vegetated foreshore" presents another example of naturebased solutions by which wave loads on coastal dikes can be reduced considerably (see Vuik et al., 2016). Such combined green and grey systems are also used to reinforce coastal protection structures while inundation occurs during storms. Within a similar approach, ecosystem-engineering species (e.g., mussel and oyster beds, willow floodplains, and marram grass) can also trap sediment and damp waves (Borsje et al., 2011).

\section{(d) Redundancy creation, diversification, de-centralization}

Redundancy creation is one of the key measures in resilience thinking (Hoekstra et al., 2018), aiming to increase resilience of the infrastructure systems. Because of redundancy and spare management, a system does not fail due to component failure (Ruijters and Stoelinga, 2015), making a redundant system more flexible when facing disruptions (Birkmann et al., 2017). However, redundancy creation does not necessarily mean that the key components of the infrastructure systems are doubled or tripled, since it can be more effective to create ringed or meshed networks (Hallegatte et al., 2019). One of the examples of making a system redundant is seen in the transport systems in which back-up trains and gradual fleet introduction over a long period (years) can increase the resilience of the network.

Diversifying the infrastructure components can also increase the resilience of the system through having a variety of elements (e.g., people, strategies, institutions, physical aspects) that contribute to the same function (Hoekstra et al., 2018). For example, in transport systems different modes of transport create more options and flexibility for the users to use alternative transportation modes in case a disruption has occurred in the network. In addition, development of rescheduling scenarios for trains helps quick recovery at the time of disruption by which the train service can be continued in a proper way. Within the power sector, diversifying generation sources can maintain a certain level of service during a disruptive event, such as nuclear power which can function at high capacity (Hallegatte et al., 2019).

De-centralization and detaching physical components of a networked infrastructure is another way of creating resilience for these systems. This measure is often applicable for power supply, thanks to the widespread introduction of renewable energy sources such as wind, solar, and biomass (Birkmann et al., 2017). De-centralization is also a solution to promote resilience of the water infrastructures referring to smalland medium-sized systems (e.g., wastewater-recycling and rainwater-harvesting infrastructure), which rely on locally available water sources (Leigh and Lee, 2019). Notably, all three measures of "redundancy creation", "diversification", and "de-centralization" can contribute to the three system abilities to absorb, respond, and recover.

\section{(e) Modeling approaches and other alternative measures}

The available literature provides a number of modeling approaches used in resilience engineering. For example, Kiel et al. (2016) conducted a study in which resilience of transport systems exposed to extreme weather events was assessed by using a decision support system. Siegel and Schraagen (2014) analyzed possible degradation of a railway system's resilience by developing a weak-resilience-signal model. Within the same sector, Román-De La Sancha et al. (2019) conducted a study of the accuracy of damage identification models (i.e., fragility curves) for urban bridges, tunnels, main roads, and metro stations affected by earthquakes to provide a better insight into the applicability of these models in seismic vulnerability and resilience assessments. Such damage identification models are extended to damage recov- 
ery scenarios to explore the resilience of VIS for a given postdisaster recovery scenario (see Do and Jung, 2018). Enhancing the resilience of the VIS can also be achieved in other ways, e.g., by improving the information flow across organizational levels (from individual to society) and adapting new technology such as social media in order to coordinate data for use (Shittu et al., 2018).

Reducing exposure and vulnerabilities of the infrastructure to natural hazards can also be regarded as a helpful measure in increasing system resilience. Some examples include building power systems far away from low-lying flooding areas, excavation of deeper foundations for power and water treatment plants, or elevating infrastructure and protecting it by higher flood protection structures (Hallegatte et al., 2019). In addition, enhancing resilience of the infrastructures can be carried out by minimizing the likely disturbances and failures through down-scaling of the assets in terms of their functionalities and services provided (e.g., constructing smaller dike rings or down-scaling drinking-water systems).

As another approach, risk assessment is used as a necessity for designing infrastructure systems within the context of resilience engineering; however opinions are different in terms of the interconnection between these two concepts (as referred to in Sect. 4.1f). Risk assessment can be carried out by using different methods and analysis including fault trees, the four-eyes principle, and safe-fail mechanisms. These methods provide qualitative metrics highlighting the root causes of the system failure and quantitative metrics dealing with the probability, cost, and impact of a disruption (Kumar and Stoelinga, 2017). For example, the fault tree is a graphical method that models the propagation of failures through the system, investigating the dependability of all components' failures, to find out whether or not all failures lead to a system failure (Ruijters and Stoelinga, 2015). Such risk-related methods can improve the ability of a system to monitor, anticipate, and absorb disturbances. Risk assessment is more applicable for assessing the high-tech infrastructure systems that are at risk of self-failure, cyber-attacks, and human errors (e.g., flood protection systems, power plants, telecommunication equipment). However, a limitation of these methods is that they may only be used for well-modeled systems and not for unanticipated surprises. The models also run into difficulties with highly complex systems with multiple interdependencies that increase exponentially.

\subsubsection{Non-engineering measures}

\section{(a) Cognitive approach}

A cognitive approach helps to determine how system controllers think, perceive, behave, and decide at the time of failure or disruption. This approach provides better insight to learn from the previous failures (fifth ability in Fig. 4), supporting the systems engineers to be aware of what fail- ures have occurred and why so that they can control or avoid future similar failures (Pearson et al., 2018).

\section{(b) Team reflection and knowledge sharing}

A resilient infrastructure system should depend on a network of connections, enabling it to incorporate other sources/information through connections with other organizations at the time of disruptions. In doing so, team reflection helps to make resilience-related knowledge explicit (Siegel and Schraagen, 2017a) and to improve learning from the previous events. Resilience knowledge sharing, education, and guidance among the users and stakeholders are the foundation for the designing, operating, and functioning of the resilient infrastructure such as flood-resilient integrated systems (Pearson et al., 2018). According to Hickford et al. (2018), knowledge sharing improves the effectiveness and adaptability of responses (referring to the "responding" ability of a system) to natural and human-induced hazards through developing and sharing resilience policies and guidelines among stakeholders. Such collaborations can help to develop the concept of resilience engineering in infrastructure design and operation, feeding back into the planning and adaptation procedures (Schippers et al., 2014).

\section{(c) "Human-centered design" approach}

Human centeredness is a core quality of systems design (Van der Bijl-Brouwer and Dorst, 2017). A human-centered design approach presents a framework which aims to empower all the actors, people, and stakeholders of an integrated system, by actively involving those who can interact with changes and development processes. Applying this approach as a design and management framework to the infrastructure systems, the technical and social aspects of the system can be integrated with a focus on two goals: (1) to make sure that human needs are addressed and (2) to make sure that the framework fulfills its purpose by continuously addressing the human needs in a changing environment. Therefore, using this framework, the system has to adapt to changes and to recover, addressing the needs of people (contributing to the system's abilities "respond" and "recover"). Considering this objective, the resilience concept is already incorporated (as a goal) within this context while also being linked to the processes to ensure that all stakeholders are involved to achieve the goal. For example, in the transport sector, Van den Beukel and van der Voort (2017) conducted a study to assess drivers' interaction with partially automated driving systems. This was carried out by proposing an assessment framework that allows designers to analyze driver support within different simulated traffic scenarios.

\subsubsection{Governance}

Governance is a key element of infrastructure resilience which includes decision-making procedures, tools, and mon- 
itoring used by governmental organizations and their associated partners to ensure that infrastructure services are available to people (OECD, 2015). For example, preparedness is one of the important approaches to ensure that systems are able to cope with sudden shocks and future pressures (Majithia, 2014). Hallegatte et al. (2019) suggested that the first step in making infrastructures resilient should be to make them reliable in normal conditions through having proper governance in infrastructure design, operation, maintenance, and financing phases. According to this suggestion, substantial investments in the regular maintenance of the current systems are of utmost importance, given that such investments in planning, in the initial stage of the projects and in the maintenance phase is considerably greater than the repairs or reconstruction costs after a disruptive event. In line with this perspective, Shittu et al. (2018) also highlighted the role of sustained investment, continuous monitoring, and data collection in having an effective emergency response after a disaster occurs. In addition, Hallegatte et al. (2019) pointed out that reducing the exposure and vulnerability of the systems to hazards is another way of promoting resilience of infrastructures.

\subsection{Recent applications in literature}

To identify to what extent the presented measures are applied in practice, here the recent literature is reviewed with a focus on the application of resilience engineering to the domains of transport, water, power, and telecommunication. In doing so, we include both studies that focus on initial phases of a design process (e.g., assessment or analysis of resilience) and studies that design, analyze, or evaluate interventions to enhance or increase resilience. Table 1 provides an overview of the selected examples, highlighting aims, approaches used, and type of shocks/pressures considered in these 50 studies. According to Table 1, transport and water infrastructures are generally among the most commonly (recent) analyzed systems, compared to the studies related to enhancing resilience of the telecommunication infrastructures that appear to be rather limited in the recent literature. In addition, studies have been conducted to analyze and improve resilience of the entire network of infrastructures (combined systems) that are affected by varied natural and human-induced shocks and pressures.

With respect to the methods and approaches used, knowledge sharing is a method applied among the four VIS. For example, Siegel and Schraagen (2017a, b) conducted an observational study on how a team of rail signallers can contribute to the resilience of rail infrastructures by providing valuable team reflection and collaborative sense-making in making resilience-related knowledge explicit. This knowledge was made explicit by a tool that provided weak resilience signals to the team, such that the team members could reflect on those signals and make implicit knowledge explicit and shared. Similarly, Majithia (2014) and Giov- inazzi et al. (2017) conducted studies within the power and telecommunication systems, respectively, in which improvement of the infrastructure's resilience was analyzed through sharing knowledge and collaborations among different stakeholders. As another method of increasing infrastructure resilience, risk assessment has been commonly used in the studies conducted by Ruijters and Stoelinga (2016), Hall et al. (2016), Do and Jung (2018), Mao et al. (2018), Wang et al. (2019), and Tsavdaroglou et al. (2018). The selected studies also highlight that within the water sector, combining green and grey infrastructures (nature-based solutions) is the most frequently used approach to increase a system's resilience (e.g., Hulscher et al., 2014; Augustijn et al., 2014; Demuzere et al., 2014; Borsje et al., 2017; Augustijn et al., 2018; Beery, 2018; Vuik et al., 2019).

While knowledge sharing, risk assessment, and naturebased solutions present the commonly used approaches in recent applications, little appears to be known about increasing resilience of VIS by using other measures, such as diversification, de-centralization, cognitive approaches, and humancentered design frameworks. Field and Look (2018) and Bakhshipour et al. (2019) presented two of the few examples in which systems thinking and de-centralization approaches were applied to quantify infrastructure resilience and to optimize drainage systems performance, respectively.

\section{Concluding remarks}

\subsection{General observations and main findings of this article}

This article aimed at providing a systematic review on designing resilient VIS by carrying out a coherent literature review and analyzing recent examples of resilience engineering in practice. In doing so, we defined VIS as integrated socialecological-technical systems, highlighting the inter-sectoral, as well as cross-sectoral, dependencies within these systems. The conceptual resilience framework presented in this article emphasizes inter-sectoral connections indicating that infrastructure resilience is dependent not only on the technical resilience and engineering characteristics of the system but also on the resilience of the two other sub-systems (i.e., ecological and social) and their mutual interactions.

Exploring diverse definitions and interpretations of resilience concepts within an infrastructure context, in this article, we presented our own definition of resilient VIS which is derived from the capacity-oriented approach and is referred to as systems with ability to (i) anticipate and absorb disturbances, (ii) adapt/transform in response to changes, (iii) recover, and (iv) learn from prior unforeseen events.

In addition, two types of challenges (i.e., conceptual tensions and challenges in practice and in the fields of application) related to the design of resilient VIS were identified and explored, providing a relation to the three components of the 


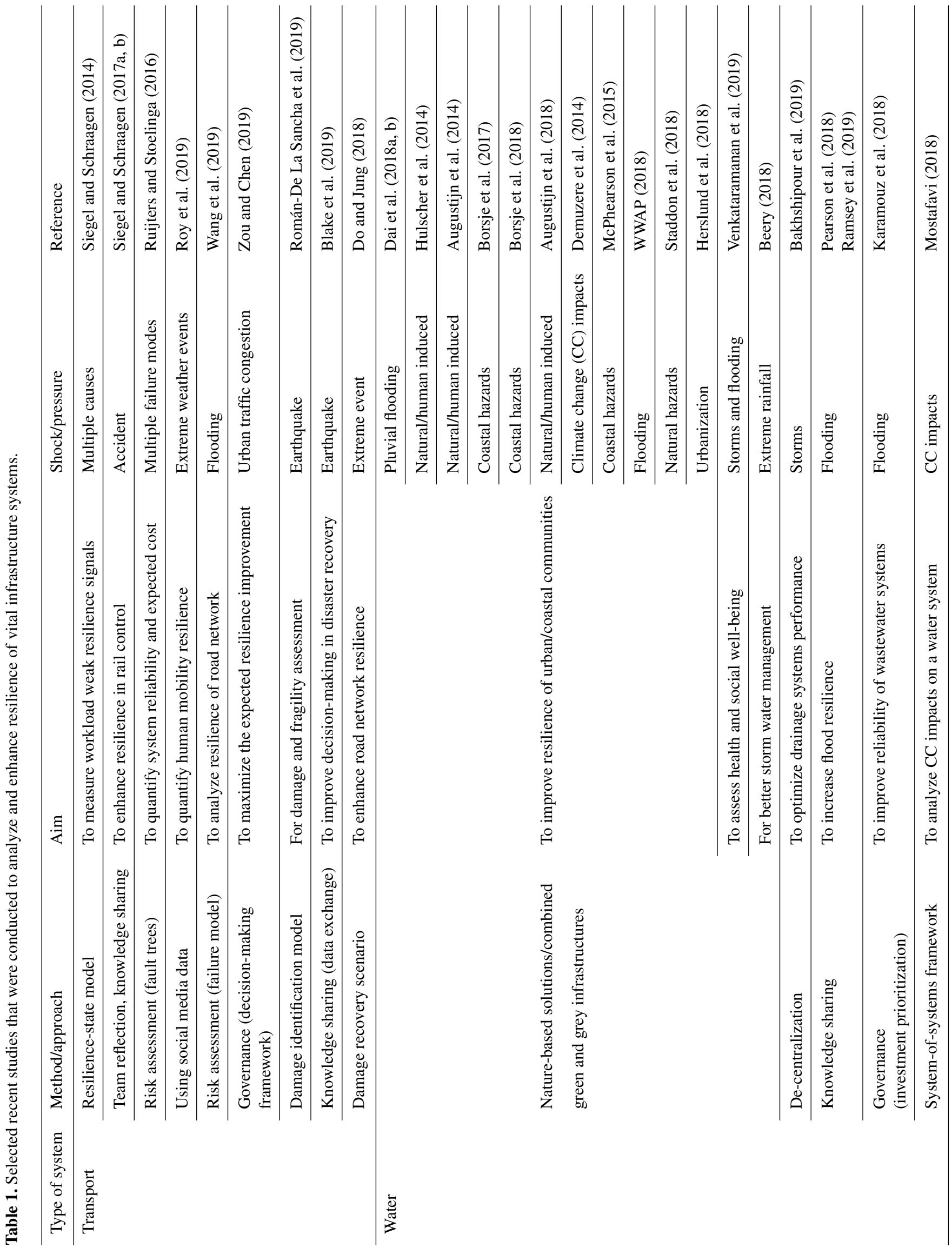




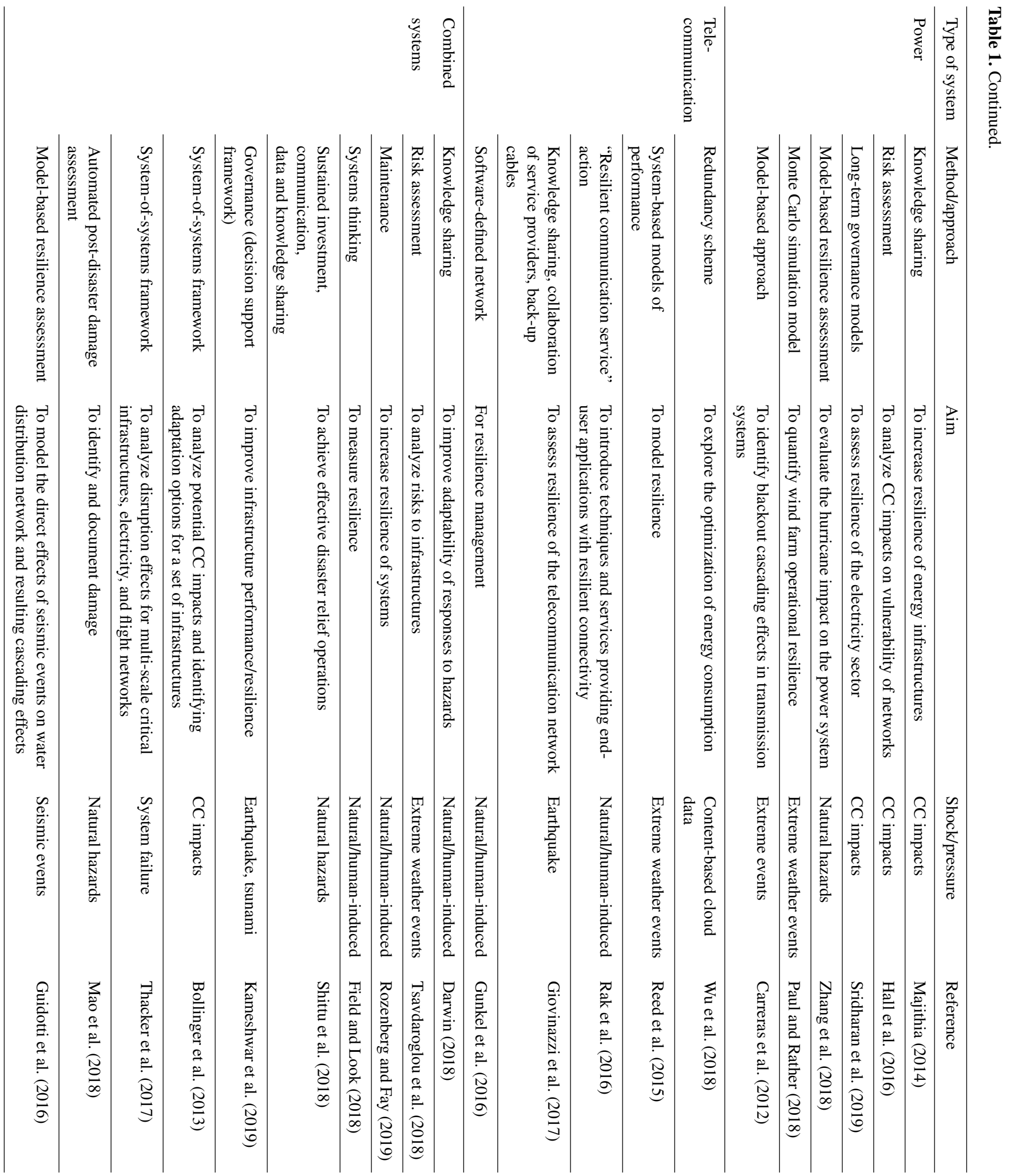


system: technical (physical asset), ecological (environment), and social (actor/user). This analysis revealed that most of the challenges arise equally from the three components; however, some of the debates such as a positive or neutral attitude to the resilience concept have mainly resulted from the different connotations and interpretations of the resilience engineering concept among users and actors. The results of the literature review also showed that the infrastructure systems are often being built with a poorly applied concept of resilience engineering that is not explicitly and practically incorporated into design and management procedures.

The engineering and non-engineering measures to increase resilience of VIS were also identified and analyzed in relation to the five main abilities required for a resilient system (i.e., anticipate and monitor, absorb, respond, recover, and learn from the past). This analysis showed that (1) engineering-based measures (e.g., nature-based, redundancy creation, remote sensing techniques) mostly contribute to the three system capabilities - absorption, response, and recovery - and (2) non-engineering methods (e.g., cognitive approaches, team reflection and knowledge sharing, and human-centered design) mostly highlight the importance of the social aspects of the system, playing an important role in improving a system's ability especially in terms of anticipating and monitoring, responding, and learning from previous experiences. Notably, governance and sustained investment can facilitate better implementation of both types of measures and provide effective measures in promoting all the five system abilities mentioned above.

Analysis of the selected 50 recent studies on improving infrastructure resilience resulted in the following main observations: (1) transport systems (often with one mode of transport) and water infrastructures are the most commonly studied systems; (2) knowledge sharing, risk assessment, the system-of-systems approach, and nature-based solutions constitute the approaches that are frequently used in recent applications; (3) natural hazards and climate change impacts represent the major sources of shocks and pressures that have been studied. However, analysis of system resilience due to the disruptions caused by human errors (e.g., accident in transport systems), cyber-attacks, terrorism, and urbanization appear to be less explored in the current literature.

\subsection{Future developments and research agenda}

This review article highlights the need for further assessment of the integration between social-ecological-technical aspects of infrastructures and analysis of how the resilience of entire VIS depends on the resilience of each sub-system. The findings of this review also point to the necessity of developing studies on understanding the complex cascading effects of failures and disturbances among the network of infrastructures and strong dependencies of systems on each other's functionality. However, recent applications show the popularity of the emerging approaches (e.g., system of sys- tems) in understanding the interdependencies of small-scale systems in one or two specific sectors. Within this topical area, more studies need to be conducted on the development of such integrated approaches for improving resilience of the large-scale VIS by analyzing the interlinked networks across different sectors. Addressing this need is of utmost importance, since the technological evolution of the systems, together with increasing uncertainties related to the global pressures such as urbanization and climate change impacts, seems to introduce more complexity into and interdependencies between the VIS.

It is expected that future standards for designing infrastructures (e.g., flood defenses) will become less conservative as soon as resilience thinking and post-disaster recovery of the infrastructures are explicitly considered in the design regulations and decision-making procedures. More inclusion of the recovery process in designing and decision-making procedures may result in replacing the long-term standards (that may not be well applicable for a sudden shock) with shortterm and urgent agreements that can be accepted by both policy makers and stakeholders for better management of a very sudden change/failure in the system.

There should also be more emphasis on the role of regular maintenance and understanding the performance of the current infrastructure systems, especially the ones that are not supposed to work well (due to their short lifetime) but are still functioning properly, even at the time of a short disruption or big disasters. Therefore, one of the focal areas of future studies in designing resilient infrastructures should be an analysis of what worked well in the system rather than only looking at what went wrong during a disturbance. Within this perspective, resilience engineering has to consider a larger view of not only human errors but also human capabilities and regular maintenance of the infrastructure that would increase the efficiency/function of a system in many cases. A cognitive approach that appears to have been less investigated in the current resilience literature offers an applicable measure for better understanding of this important issue.

It is also suggested to have a different way of thinking about the resilience of infrastructure systems. Resilience should be considered a relative quantity, rather than an absolute quantity. Infrastructure systems are better designed in a way to become "more resilient", rather than resilient. Therefore, instead of setting a threshold to call a system resilient, comparing a system with its previous situation is suggested. In this context, the recovery speed represents a good measure to indicate whether a system is more resilient than it used to be. However, the work described in this review also demonstrates a challenge, in that resilience measured on the ground using conventional assessment methods did not always correspond to effective recovery.

With respect to new engineering-based technology, the data provided by remote sensing techniques cannot always explain well the reason for having different level of recovery between infrastructure systems. Knowing this limitation, the 
obtained information is not yet actionable, calling for future studies on how to make the obtained data useful in identifying the factors that create different recovery characteristics (i.e., quicker/slower, complete/partial). Work is now emerging to couple image-based recovery assessment with macroeconomic agent-based modeling that aims at explaining better the observed recovery patterns. If successful, this can be used to identify socio-economic, as well as legal and political, measures to improve the process. Such efforts can provide better insight into the little-known issue of differential impacts and recovery rates across communities, as well as into feedback processes and dynamics of the systems after a shock has occurred. This may also serve as a tool for governments to find out what are the most significant responsible parameters to inform the success of recovery.

Data availability. No data sets were used in this article.

Author contributions. SM and KMW conceived the overall approach and the main conceptual design of the article. All the coauthors provided constructive inputs and helpful suggestions for improving the paper with both conceptual and practical content. SM conducted the literature review, compiled the inputs, and wrote the article.

Competing interests. The authors declare that they have no conflict of interest.

Acknowledgements. This study is conducted under the program "Engineering for a resilient world" which is being developed at the University of Twente (UT), the Netherlands. The authors are thankful for the constructive contributions of the experts and staff members of the UT in the three faculties of ET, BMS, and ITC whose views and inputs were used for this study: Karin Pfeffer, Richard Sliuzas, Jaap Kwadijk, Leo van Dongen, Mascha van der Voort, Andre Doree, Gul Ozerol, Michael Nagenborg, Marielle Stoelinga, Fenna Hoefsloot, and Kamia Handayani.

Review statement. This paper was edited by Thomas Glade and reviewed by three anonymous referees.

\section{References}

Adger, W. N.: Social and ecological resilience: are they related?, Prog. Human Geogr., 24, 347-364, https://doi.org/10.1191/030913200701540465, 2000.

Ahlborg, H., Ruiz-Mercado, I., Molander, S., and Masera, O.: Bringing Technology into Social-Ecological Systems Research-Motivations for a Socio-TechnicalEcological Systems Approach, Sustainability, 11, 2009, https://doi.org/10.3390/su11072009, 2019.
Aitsi-Selmi, A., Egawa, S., Sasaki, H., Wannous, C., and Murray, V.: The Sendai framework for disaster risk reduction: Renewing the global commitment to people's resilience, health, and well-being, Int. J. Disast. Risk Sci., 6, 164-176, https://doi.org/10.1007/s13753-015-0050-9, 2015.

Anderies, J. M., Rodriguez, A. A., Janssen, M. A., and Cifdaloz, O.: Panaceas, uncertainty, and the robust control framework in sustainability science, P. Natl. Acad. Sci. USA, 104, 15194-15199, https://doi.org/10.1073/pnas.0702655104, 2007.

Anderies, J., Folke, C., Walker, B., and Ostrom, E.: Aligning key concepts for global change policy: robustness, resilience, and sustainability, Ecol. Soc., 18, 2, 2013.

Argyroudis, S., Hofer, L., Zanini, M. A., and Mitoulis, S. A.: Resilience of critical infrastructure for multiple hazards: Case study on a highway bridge, in: ICONHIC 2019 2nd International Conference on Natural Hazards and Infrastructure, 23-26 June 2019, Chania, 23-26, 2019.

Augustijn, D. C. M., Schielen, R., and Hulscher, S. J. M. H.: RiverCare: towards self-sustaining multifunctional rivers, in: EGU General Assembly Conference Abstracts, Delft, the Netherlands, 13-14, 2014.

Augustijn, D. C. M., Hulscher, S. J. M. H., and Schielen, R. M. J.: RiverCare: Researching measures to prepare multi-functional rivers for the next century, in: 5th IAHR Europe Congress: New Challenges in Hydraulic Research and Engineering Research Publishing, 12-14 June 2018, Trento, Italy, 473-474, 2018.

Bakhshipour, A. E., Dittmer, U., Haghighi, A., and Nowak, W.: Hybrid green-blue-gray decentralized urban drainage systems design, a simulation-optimization framework, J. Environ. Manage., 249, 109364, https://doi.org/10.1016/j.jenvman.2019.109364, 2019.

Batty, M.: The size, scale, and shape of cities, Science, 319, 769771, https://doi.org/10.1126/science.1151419, 2008.

Beery, T.: Engaging the Private Homeowner: Linking Climate Change and Green Storm Water Infrastructure, Sustainability, 10, 4791, https://doi.org/10.3390/su10124791, 2018.

Bene, C. and Doyen, L.: From resistance to transformation: a generic metric of resilience through viability, Earth's Future, 6, 979-996, https://doi.org/10.1002/2017EF000660, 2018.

Berkes, F., Colding, J., and Folke, C.: Navigating Social-Ecological Systems: Building Resilience for Complexity and Change, Cambridge University Press, Cambridge, UK, 393 pp., 2003.

Biggs, R., Schlüter, M., Biggs, D., Bohensky, E. L., BurnSilver, S., Cundill, G., Dakos, V., Daw, T. M., Evans, L. S., Kotschy, K., and Leitch, A. M.: Toward principles for enhancing the resilience of ecosystem services, Annu. Rev. Environ. Resour., 37, 421-448, https://doi.org/10.1146/annurev-environ-051211-123836, 2012.

Birkmann, J., Wenzel, F., Greiving, S., Garschagen, M., Vallee, D., Nowak, W., Welle, T., Fina, S., Goris, A., Rilling, B., and Fiedrich, F.: Extreme Events, Critical Infrastructures, Human Vulnerability and Strategic Planning: Emerging Research Issues, J. Ext. Event., 3, 1-25, https://doi.org/10.1142/S2345737616500172, 2017.

Blake, D. M., Stevenson, J., Wotherspoon, L., Ivory, V., and Trotter, M.: The role of data and information exchanges in transport system disaster recovery: A New Zealand case study, Int. J. Disast. Risk Reduct., 39, 101124 , https://doi.org/10.1016/j.ijdrr.2019.101124, 2019. 
Bollinger, L. A., Bogmans, C. W. J., Chappin, E. J. L., Dijkema, G. P. J., Huibregtse, J. N., Maas, N., Schenk, T., Snelder, M., van Thienen, P., de Wit, S., and Wols, B.: Climate adaptation of interconnected infrastructures: a framework for supporting governance, Reg. Environ. Change, 14, 919-931, https://doi.org/10.1007/s10113-013-0428-4, 2013.

Bolton, R. and Foxon, T. J.: Infrastructure transformation as a sociotechnical process-Implications for the governance of energy distribution networks in the UK, Technol. Forecast. Social Change, 90, 538-550, https://doi.org/10.1016/j.techfore.2014.02.017, 2015.

Borsje, B. W., van Wesenbeeck, B. K., Dekker, F., Paalvast, P., Bouma, T. J., van Katwijk, M. M., and de Vries, M. B.: How ecological engineering can serve in coastal protection, Ecol. Eng., 37, 113-122, https://doi.org/10.1016/j.ecoleng.2010.11.027, 2011.

Borsje, B. W., de Vries, S., Janssen, S. K., Luijendijk, A. P., and Vuik, V.: Building with nature as coastal protection strategy in The Netherlands, in: Living Shorelines, CRC Press, Florida, USA, 137-156, 2017.

Borsje, B. W., Willemsen, P., and Hulscher, S. J. M. H.: Vegetated foreshores as coastal protection strategy: coping with uncertainties and implementation, Coast. Eng. Proceed., 1, 36, https://doi.org/10.9753/icce.v36.risk.7, 2018.

Bouchon, S.: The vulnerability of interdependent critical infrastructures systems: Epistemological and conceptual state of the art, Institute for the Protection and Security of the Citizen, Joint Research Centre, European Commission, Italy, 99 pp., 2006.

Browder, G., Ozment, S., Rehberger Bescos, I., Gartner, T., and Lange, G. M.: Integrating Green and Gray: Creating Next Generation Infrastructure, World Bank and World Resources Institute, Washington, D.C., available at: https://openknowledge. worldbank.org/handle/10986/31430 (last access: 27 June 2020), 2019.

Brown, A., Dayal, A., and Rumbaitis Del Rio, C.: From practice to theory: emerging lessons from Asia for building urban climate change resilience, Environ. Urbaniz., 24, 531-556, https://doi.org/10.1177/0956247812456490, 2012.

Brown, J. M., Morrissey, K., Knight, P., Prime, T. D., Almeida, L. P., Masselink, G., Bird, C. O., Dodds, D., and Plater, A. J.: A coastal vulnerability assessment for planning climate resilient infrastructure, Ocean Coast. Manage., 163, 101-112, https://doi.org/10.1016/j.ocecoaman.2018.06.007, 2018.

Bujones, A. K., Jaskiewicz, K., Linakis, L., and McGirr, M.: A framework for analyzing resilience in fragile and conflictaffected situations, Columbia University SIPA, New York, USA, 2013.

Carreras, B. A., Newman, D. E., and Dobson, I.: Determining the vulnerabilities of the power transmission system, in: IEEE 45th Hawaii International Conference on System Sciences, 4-7 January 2012, Maui, HI, USA, 2044-2053, https://doi.org/10.1109/HICSS.2012.208, 2012.

Chaffin, B. C., Garmestani, A. S., Gunderson, L. H., Benson, M. H., Angeler, D. G., Arnold, C. A., Cosens, B., Craig, R. K., Ruhl, J. B., and Allen, C. R.: Transformative environmental governance, Annu. Rev. Environ. Resour., 41, 399-423, https://doi.org/10.1146/annurev-environ-110615-085817, 2016.

Chelleri, L.: From the Resilient City to Urban Resilience, a review essay on understanding and integrating the resilience perspective for urban systems, Documents d'anàlisi geogràfica, 58, 287-306, https://doi.org/10.5565/rev/dag.175, 2012.

Cimellaro, G. P., Renschler, C., Reinhorn, A. M., and Arendt, L.: PEOPLES: a framework for evaluating resilience, J. Struct. Eng., 142, 04016063, https://doi.org/10.1061/(ASCE)ST.1943541X.0001514, 2016.

Clark, S. S., Seager, T. P., and Chester, M. V.: A capabilities approach to the prioritization of critical infrastructure, Environ. Syst. Decis., 38, 339-352, https://doi.org/10.1007/s10669-0189691-8, 2018.

Coaffee, J.: Towards next-generation urban resilience in planning practice: From securitization to integrated place making, Plan. Pract. Res., 28, 323-339, https://doi.org/10.1080/02697459.2013.787693, 2013

Connelly, E. B., Allen, C. R., Hatfield, K., Palma-Oliveira, J. M., Woods, D. D., and Linkov, I.: Features of resilience, Environ. Syst. Decis., 37, 46-50, https://doi.org/10.1007/s10669017-9634-9, 2017.

Cote, M. and Nightingale, A. J.: Resilience thinking meets social theory: Situating social change in socio-ecological systems (SES) research, Prog. Human Geogr., 1, 475-489, https://doi.org/10.1177/0309132511425708, 2011.

Covello, V. T. and Merkhoher, M. W.: Risk Assessment Methods, Approaches for Assessing Health and Environmental Risks, Springer Science and Business Media, New York, USA, 2013.

Dai, L., Worner, R., and van Rijswick, H. F.: Rainproof cities in the Netherlands: approaches in Dutch water governance to climateadaptive urban planning, Int. J. Water Resour. Dev., 34, 652-674, https://doi.org/10.1080/07900627.2017.1372273, 2018a.

Dai, L., van Rijswick, H. F., Driessen, P. P., and Keessen, A. M.: Governance of the Sponge City Programme in China with Wuhan as a case study, Int. J. Water Resour. Dev., 34, 578-596, https://doi.org/10.1080/07900627.2017.1373637, 2018b.

Darwin: Expect the unexpected and know how to respond, available at: https://h2020darwin.eu/, last access: 17 September 2019.

Davoudi, S., Shaw, K., Haider, L. J., Quinlan, A. E., Peterson, G. D., Wilkinson, C., Funfgeld, H., McEvoy, D., Porter, L., and Davoudi, S.: Resilience: a bridging concept or a dead end? "Reframing" resilience: challenges for planning theory and practice interacting traps: resilience assessment of a pasture management system in Northern Afghanistan urban resilience: what does it mean in planning practice? Resilience as a useful concept for climate change adaptation? The politics of resilience for planning: a cautionary note: edited by: Davoudi, S. and Porter, L., Plan. Theory Pract., 13, 299-333, https://doi.org/10.1080/14649357.2012.677124, 2012.

Dekker, S., Hollnagel, E., Woods, D., and Cook, R.: Resilience Engineering: New directions for measuring and maintaining safety in complex systems, Lund University School of Aviation, Lund, $1-6,2008$.

De Koning, K., Filatova, T., Need, A., and Bin, O.: Avoiding or mitigating flooding: Bottom-up drivers of urban resilience to climate change in the USA, Global Environ. Change, 59, 101981, https://doi.org/10.1016/j.gloenvcha.2019.101981, 2019.

Demuzere, M., Orru, K., Heidrich, O., Olazabal, E., Geneletti, D., Orru, H., Bhave, A. G., Mittal, N., Feliu, E., and Faehnle, M.: Mitigating and adapting to climate change: Multi-functional and multi-scale assessment of green ur- 
ban infrastructure, J. Environ. Manage., 146, 107-115, https://doi.org/10.1016/j.jenvman.2014.07.025, 2014.

De Regt, A., Siegel, A. W., and Schraagen, J. M.: Toward quantifying metrics for rail-system resilience: identification and analysis of performance weak resilience signals, Cognit. Technol. Work, 18, 319-331, https://doi.org/10.1007/s10111-015-0356-9, 2016.

De Schipper, M. A., de Vries, S., Ruessink, G., de Zeeuw, R. C., Rutten, J., van Gelder-Maas, C., and Stive, M. J.: Initial spreading of a mega feeder nourishment: Observations of the Sand Engine pilot project, Coast. Eng., 111, 23-38, https://doi.org/10.1016/j.coastaleng.2015.10.011, 2016.

De Vriend, H. J. and Van Koningsveld, M.: Building with Nature: Thinking, Acting and Interacting Differently, Ecoshape, Dordrecht, the Netherlands, 2012.

Do, M. and Jung, H.: Enhancing Road Network Resilience by Considering the Performance Loss and Asset Value, Sustainability, 10, 4188, https://doi.org/10.3390/su10114188, 2018.

Donovan, B. and Work, D. B.: Empirically quantifying city-scale transportation system resilience to extreme events, Transport. Res. Pt. C, 79, 333-346, https://doi.org/10.1016/j.trc.2017.03.002, 2017.

EC: European Commission: Communication from the Commission on Critical Infrastructure Protection in the fight against terrorism, 702 Final, COM, Brussels, Belgium, 2004.

EC: European Commission: Towards an EU Research and Innovation policy agenda for nature-based solutions and re-naturing cities, final report of the Horizon 2020, 16 June 2020, Brussels, Belgium, 2015.

EC: Biodiversity Information System for Europe, Green infrastructure, available at: https://biodiversity.europa.eu/topics/ green-infrastructure/, last access: 12 September 2019.

Eidsvig, U. and Tagg, A.: SOTA of Modelling and Simulation Approaches, used currently to assess CI vulnerability, INTACT Deliverable D 4.1, project co-funded by the European Commission under the 7th Frame-work Programme, Wallingford, 2015.

Eisenberg, D. A., Park, J., and Seager, T. P.: Sociotechnical network analysis for power grid resilience in South Korea, Complexity, 2017, 3597010, https://doi.org/10.1155/2017/3597010, 2017.

Field, C. and Look, R.: A value-based approach to infrastructure resilience, Environ. Syst. Decis., 38, 292-305, https://doi.org/10.1007/s10669-018-9701-x, 2018.

Field, C. B., Barros, V., Stocker, T. F., Dahe, Q., Dokken, D. J., Ebi, K. L., Mastrandrea, M. D., Mach, K. J., Plattner, G. K., Allen, S. K., and Tignor, M.: Managing the Risks of Extreme Events and Disasters to Advance Climate Change Adaptation: A Special Report of Working Groups I and II of the Intergovernmental Panel on Climate Change, IPCC, Cambridge University Press, Cambridge, UK, 2012.

Filatova, T., Mulder, J. P., and van der Veen, A.: Coastal risk management: how to motivate individual economic decisions to lower flood risk, Ocean Coast. Manage., 54, 164-172, https://doi.org/10.1016/j.ocecoaman.2010.10.028, 2011.

Filiatrault, A., and Sullivan, T.: Performance-based seismic design of nonstructural building components: The next frontier of earthquake engineering, Earthq. Eng. Eng. Vibrat., 13, 17-46, https://doi.org/10.1007/s11803-014-0238-9, 2014.

Fischer, J., Gardner, T. A., Bennett, E. M., Balvanera, P., Biggs, R., Carpenter, S., Daw, T., Folke, C., Hill, R., Hughes, T. P., and Luthe, T.: Advancing sustainability through mainstreaming a social-ecological systems perspective, Curr. Opin. Environ. Sustainabil., 14, 144-149, https://doi.org/10.1016/j.cosust.2015.06.002, 2015.

Folke, C.: Resilience: The emergence of a perspective for socialecological systems analyses, Global Environ. Change, 16, 253267, https://doi.org/10.1016/j.gloenvcha.2006.04.002, 2006.

Frangopol, D. M. and Bocchini, P.: Bridge network performance, maintenance and optimisation under uncertainty: accomplishments and challenges, Struct. Infrastruct. Eng., 8, 341-356, https://doi.org/10.1080/15732479.2011.563089, 2012

Galderisi, A.: The resilient city metaphor to enhance cities' capabilities to tackle complexities and uncertainties arising from current and future climate scenarios, in: Smart, resilient and transition cities, Emerging approaches and tools for a climate-sensitive urban development, edited by: Galderisi, A. and Colucci, A., Elsevier, Amsterdam, 11-18, 2018.

Galiforni Silva, F., Wijnberg, K. M., de Groot, A. V., and Hulscher, S. J. M. H.: The effects of beach width variability on coastal dune development at decadal scales, Geomorphology, 329, 5869, https://doi.org/10.1016/j.geomorph.2018.12.012, 2019.

Ganjurjav, H., Zhang, Y., Gornish, E. S., Hu, G., Li, Y., Wan, Y., and Gao, Q.: Differential resistance and resilience of functional groups to livestock grazing maintain ecosystem stability in an alpine steppe on the QinghaiTibetan Plateau, J. Environ. Manage., 251, 109579 , https://doi.org/10.1016/j.jenvman.2019.109579, 2019.

Gardoni, P.: Routledge Handbook of Sustainable and Resilient Infrastructure, Routledge, New York, 2018.

Gardoni, P. and Murphy, C.: Society-based design: promoting societal well-being by designing sustainable and resilient infrastructure, Sustain. Resil. Infrastruct., 5, 4-19, https://doi.org/10.1080/23789689.2018.1448667, 2018.

Ghaffarian, S. and Kerle, N.: Towards post-disaster debris identification for precise damage and recovery assessments from UAV and satellite images, Int. Arch. Photogramm. Remote Sens. Spat. Inf. Sci., XLII-2/W13, 297-302, https://doi.org/10.5194/isprsarchives-XLII-2-W13-297-2019, 2019.

Ghaffarian, S., Kerle, N., Pasolli, E., and Jokar Arsanjani, J.: Post-disaster building database updating using automated deep learning: An integration of pre-disaster OpenStreetMap and multi-temporal satellite data, Remote Sens., 11, 2427, https://doi.org/10.3390/rs11202427, 2019.

Giovinazzi, S., Austin, A., Ruiter, R., Foster, C., Nayyerloo, M., Nair, N. K., and Wotherspoon, L.: Resilience and fragility of the telecommunication network to seismic events: Evidence after the kaikōura (New Zealand) earthquake, Bull. New Zeal. Soc. Earthq. Eng., 50, 318-328, https://doi.org/10.5459/bnzsee.50.2.318-328, 2017.

Guidotti, R., Chmielewski, H., Unnikrishnan, V., Gardoni, P., McAllister, T., and van de Lindt, J.: Modeling the resilience of critical infrastructure: The role of network dependencies, Sustain. Resil. Infrastruct., 1, 153-168, https://doi.org/10.1080/23789689.2016.1254999, 2016.

Guidotti, R., Gardoni, P., and Chen, Y.: Network reliability analysis with link and nodal weights and auxiliary nodes, Struct. Safe., 65, 12-26, https://doi.org/10.1016/j.strusafe.2016.12.001, 2017.

Gunderson, L. H. and Holling, C. S.: Understanding Transformations in Human and Natural Systems, Island Press, Washington, D.C., 2002. 
Gunkel, M., Wissel, F., Blendin, J., Herrmann, D., Wichtlhuber, M., and Hausheer, D.: Efficient partial recovery of flexible-rate transceivers with sdn-based asymmetric multipath routing of ip traffic, in: Photonic Networks, 17th ITG-Symposium, Proceedings of VDE, 12-13 May 2016, Leipzig, Germany, 1-6, 2016.

Hale, A., and Heijer, T.: Defining resilience, in: Resilience engineering: concepts and precepts, edited by: Woods, D. D. and Hollnagel, E. Ashgate, Farnham, 35-40, 2006.

Hall, J. W., Tran, M., Hickford, A. J., and Nicholls, R. J.: The future of national infrastructure: A system-of-systems approach, Cambridge University Press, Cambridge, 2016.

Hallegatte, S., Rentschler, J., and Rozenberg, J.: Resilient Infrastructure: A Lifeline for Sustainable Development, The World Bank, Washington, DC, https://doi.org/10.1596/978-14648-1430-3_ch1, 2019.

Henry, D. and Ramirez-Marquez, J. E.: Generic metrics and quantitative approaches for system resilience as a function of time, Reliabil. Eng. Syst. Safe., 99, 114-122, https://doi.org/10.1016/j.ress.2011.09.002, 2012.

Herslund, L., Backhaus, A., Fryd, O., Jorgensen, G., Jensen, M. B., Limbumba, T. M., Liu, L., Mguni, P., Mkupasi, M., Workalemahu, L., and Yeshitela, K.: Conditions and opportunities for green infrastructure-Aiming for green, water-resilient cities in Addis Ababa and Dar es Salaam, Landsc. Urban Plan., 180, 319-327, https://doi.org/10.1016/j.landurbplan.2016.10.008, 2018.

Hickford, A. J., Blainey, S. P., Hortelano, A. O., and Pant, R.: Resilience engineering: theory and practice in interdependent infrastructure systems, Environ. Syst. Decis., 38, 278-291, https://doi.org/10.1007/s10669-018-9707-4, 2018.

Hoekstra, A. Y., Bredenhoff-Bijlsma, R., and Krol, M. S.: The control versus resilience rationale for managing systems under uncertainty, Environ. Res. Lett., 13, 103002, https://doi.org/10.1088/1748-9326/aadf95, 2018.

Holling, C. S.: Engineering resilience versus ecological resilience, in: Engineering within Ecological Constraints, edited by: Schulze, P., National Academy Press, Washington, D.C., 3144, 1996.

Holling, C. S.: Understanding the complexity of economic, ecological, and social systems, Ecosystems, 4, 390-405, https://doi.org/10.1007/s10021-001-0101-5, 2001.

Hollnagel, E., Woods, D. D., and Leveson, N.: Resilience engineering: Concepts and precepts, Ashgate Publishing, Ltd, Hampshire, UK, 2006.

Hollnagel, E.: RAG-The resilience analysis grid, Resilience engineering in practice: a guidebook, Ashgate Publishing Limited, Farnham, Surrey, 275-296, 2011.

Hollnagel, E.: Resilience engineering, available at: http: //erikhollnagel.com/ideas/resilienceengineering.html/, last access: 7 September 2019.

Hosseini, S., Barker, K., and Ramirez-Marquez, J. E.: A review of definitions and measures of system resilience, Reliabil. Eng. Syst. Safe., 145, 47-61, https://doi.org/10.1016/j.ress.2015.08.006, 2016.

Hulscher, S. J. M. H., Schielen, R. M. J., Augustijn, D. C. M., Warmink, J. J., Van der Voort, M. C., Middelkoop, H., Kleinhans, M. G., Leuven, R. S. E. W., Lenders, H. J. R., Smits, A. J. M., and Fliervoet, J. M.: Rivercare: Towards self-sustaining multifunctional rivers, in: Netherlands Centre for River Studies Conference, Delft, 13-14, 2014.

Ibanez, E., Lavrenz, S., Gkritza, K., Mejía, D., Krishnan, V., McCalley, J., and Somani, A. K.: Resilience and robustness in long-term planning of the national energy and transportation system, Int. J. Crit. Infrastruct., 12, 82-103, https://doi.org/10.1504/IJCIS.2016.075869, 2016.

Kameshwar, S., Cox, D. T., Barbosa, A. R., Farokhnia, K., Park, H., Alam, M. S., and van de Lindt, J. W.: Probabilistic decisionsupport framework for community resilience: Incorporating multi-hazards, infrastructure interdependencies, and resilience goals in a Bayesian network, Reliabil. Eng. Syst. Safe., 191, 106568, https://doi.org/10.1016/j.ress.2019.106568, 2019.

Karamouz, M., Rasoulnia, E., Olyaei, M. A., and Zahmatkesh, Z.: Prioritizing investments in improving flood resilience and reliability of wastewater treatment infrastructure, J. Infrastruct. Syst., 24, 04018021, https://doi.org/10.1061/(ASCE)IS.1943555X.0000434, 2018.

Keijsers, J. G., Giardino, A., Poortinga, A., Mulder, J. P., Riksen, M. J., and Santinelli, G.: Adaptation strategies to maintain dunes as flexible coastal flood defense in The Netherlands, Mitig. Adapt. Strat. Global Change, 20, 913-928, https://doi.org/10.1007/s11027-014-9579-y, 2015.

Kerle, N.: Satellite-based damage mapping following the 2006 Indonesia earthquake - How accurate was it, Int. J. Appl. Earth Obs. Geoinf., 12, 466-476, https://doi.org/10.1016/j.jag.2010.07.004, 2010.

Kerle, N.: Disasters: risk assessment, management, and post - disaster studies using remote sensing, in: Remote sensing of water resources, disasters, and urban studies (Remote sensing handbook, 3), edited by: Thenkabail, P. S., CRC Press, Boca Raton, 455-481, 2015.

Kerle, N., Ghaffarian, S., Nawrotzki, R., Leppert, G., and Lech, M.: Evaluating resilience-centered development interventions with remote sensing, Remote Sensing, 11, 2511, https://doi.org/10.3390/rs11212511, 2019a.

Kerle, N., Nex, F., Duarte, D., and Vetrivel, A.: UAV-based structural damage mapping - Results from 6 years of research in two European projects, Int. Arch. Photogram Remote Sens. Spatial Inf. Sci., XLII-3/W8, 187-194, https://doi.org/10.5194/isprsarchives-XLII-3-W8-187-2019, 2019b.

Kiel, J., Petiet, P., Nieuwenhuis, A., Peters, T., and van Ruiten, K.: A decision support system for the resilience of critical transport infrastructure to extreme weather events, Transport. Res. Proced., 14, 68-77, https://doi.org/10.1016/j.trpro.2016.05.042, 2016.

Kim, D. and Lim, U.: Urban resilience in climate change adaptation: A conceptual framework, Sustainability, 8, 405, https://doi.org/10.3390/su8040405, 2016.

Klijn, F., Asselman, N., and Wagenaar, D.: Room for Rivers: Risk Reduction by Enhancing the Flood Conveyance Capacity of the Netherlands' Large Rivers, Geosciences, 8, 224, https://doi.org/10.3390/geosciences8060224, 2018.

Koks, E. E., Rozenberg, J., Zorn, C., Tariverdi, M., Vousdoukas, M., Fraser, S. A., Hall, J. W., and Hallegatte, S.: A global multihazard risk analysis of road and railway infrastructure assets, Nature communications, 10, 2677, https://doi.org/10.1038/s41467019-10442-3, 2019. 
Kothuis, B. and Kok, M.: Integral Design of Multifunctional Flood Defenses: Multidisciplinary Approaches and Examples, Delft University Publishers, Delft, ISBN 978-94-6186-808-4, 2017.

Kumar, R. and Stoelinga, M.: Quantitative security and safety analysis with attack-fault trees, in: 2017 IEEE 18th International Symposium on High Assurance Systems Engineering (HASE), 12-14 January 2017, Singapore, 25-32, https://doi.org/10.1109/HASE.2017.12, 2017.

Kurth, M. H., Keenan, J. M., Sasani, M., and Linkov, I.: Defining resilience for the US building industry, Build. Res. Inform., 47, 480-492, https://doi.org/10.1080/09613218.2018.1452489, 2019.

Leigh, N. G. and Lee, H.: Sustainable and resilient urban water systems: The role of decentralization and planning, Sustainability, 11, 918, https://doi.org/10.3390/su11030918, 2019.

Leveson, N., Dulac, N., Zipkin, D., Cutcher-Gershenfeld, J., Carroll, J., and Barrett, B.: Engineering resilience into safety-critical systems, Resil. Eng.: Concept. Precept., Ashgate Publishing Ltd., Hampshire, UK, 95-123, 2006.

LRF: Lloyd's Register Foundation: strategy 2014-2020, London, UK, 2014.

LRF: Foresight review of resilience engineering: designing for the expected and unexpected, Lloyd's Register Foundation Report Series: No. 2015.2, London, UK, 2015.

Madni, A. M. and Jackson, S.: Towards a conceptual framework for resilience engineering, IEEE Syst. J., 3, 181-191, https://doi.org/10.1109/JSYST.2009.2017397, 2009.

Majithia, S.: Improving resilience challenges and linkages of the energy industry in changing climate, In Weather Matters for Energy, Springer, New York, NY, 113-131, https://doi.org/10.1007/978-1-4614-9221-4_5, 2014.

Mao, Z., Yan, Y., Wu, J., Hajjar, J. F., and Padlr, T.: Towards Automated Post-Disaster Damage Assessment of Critical Infrastructure with Small Unmanned Aircraft Systems, in: 2018 IEEE International Symposium on Technologies for Homeland Security (HST), 23-24 October 2018, Woburn, MA, USA, 1-6, https://doi.org/10.1109/THS.2018.8574186, 2018.

Markolf, S. A., Chester, M. V., Eisenberg, D. A., Iwaniec, D. M., Davidson, C. I., Zimmerman, R., Miller, T. R., Ruddell, B. L., and Chang, H.: Interdependent Infrastructure as Linked Social, Ecological, and Technological Systems (SETSs) to Address Lock-in and Enhance Resilience, Earth's Future, 6, 1638-1659, https://doi.org/10.1029/2018EF000926, 2018.

Martinez, M. L., Taramelli, A., and Silva, R.: Resistance and resilience: facing the multidimensional challenges in coastal areas, J. Coast. Res., 77, 1-6, https://doi.org/10.2112/SI77-001.1, 2017.

McEvoy, D., Funfgeld, H., and Bosomworth, K.: Resilience and climate change adaptation: the importance of framing, Plan. Pract. Res., 28, 280-293, https://doi.org/10.1080/02697459.2013.787710, 2013.

McPhearson, T., Andersson, E., Elmqvist, T., and Frantzeskaki, N.: Resilience of and through urban ecosystem services, Ecosyst. Serv., 12, 152-156, https://doi.org/10.1016/j.ecoser.2014.07.012, 2015.

Meadows, D. H.: Thinking in systems: A primer, Chelsea green publishing, Chelsea, 2008.

Meerow, S. and Newell, J. P.: Resilience and complexity: A bibliometric review and prospects for industrial ecology, J. Indust. Ecol., 19, 236-251, https://doi.org/10.1111/jiec.12252, 2015.
Meerow, S., Newell, J. P., and Stults, M.: Defining urban resilience: A review, Landsc. Urban Plan., 147, 38-49, 2016.

Mehvar, S., Dastgheib, A., Bamunawala, J., Wickramanayake, M., and Ranasinghe, R.: Quantitative assessment of the environmental risk due to climate change-driven coastline recession: A case study in Trincomalee coastal area, Sri Lanka, Climate Risk Management, Elsevier, the Netherlands, 100192, https://doi.org/10.1016/j.crm.2019.100192, 2019a.

Mehvar, S., Dastgheib, A., Filatova, T., and Ranasinghe, R.: A practical framework of quantifying climate change-driven environmental losses (QuantiCEL) in coastal areas in developing countries, Environ. Sci. Policy, 101, 302-310, https://doi.org/10.1016/j.envsci.2019.09.007, 2019b.

Meltzer, J. P.: Financing low carbon, climate resilient infrastructure: the role of climate finance and green financial systems, in: Climate Resilient Infrastructure: The Role of Climate Finance and Green Financial Systems, Brookings, Washington, DC, https://doi.org/10.2139/ssrn.2841918, 2016.

Mens, M. J., Klijn, F., de Bruijn, K. M., and van Beek, E.: The meaning of system robustness for flood risk management, Environ. Sci. Policy, 14, 1121-1131, https://doi.org/10.1016/j.envsci.2011.08.003, 2011.

Meyer, P. B. and Schwarze, R.: Financing climateresilient infrastructure: Determining risk, reward, and return on investment, Front. Eng. Manage., 6, 117-127, https://doi.org/10.1007/s42524-019-0009-4, 2019.

Mosalam, K. M., Alibrandi, U., Lee, H., and Armengou, J.: Performance-based engineering and multi-criteria decision analysis for sustainable and resilient building design, Struct. Safe., 74, 1-13, https://doi.org/10.1016/j.strusafe.2018.03.005, 2018.

Mostafavi, A.: A system-of-systems framework for exploratory analysis of climate change impacts on civil infrastructure resilience, Sustain. Resil. Infrastruct., 3, 175-192, https://doi.org/10.1080/23789689.2017.1416845, 2018.

Mostert, E., Gaertner, M., Holmes, P. M., O'Farrell, P. J., and Richardson, D. M.: A multi-criterion approach for prioritizing areas in urban ecosystems for active restoration following invasive plant control, Environ. Manage., 62, 1150-1167, https://doi.org/10.1007/s00267-018-1103-9, 2018.

Muneepeerakul, R. and Anderies, J. M.: Strategic behaviors and governance challenges in social-ecological systems, Earth's Future, 5, 865-876, https://doi.org/10.1002/2017EF000562, 2017.

Nagenborg, M.: Urban resilience and distributive justice, Sustain. Resil. Infrastruct., 4, 103-111, https://doi.org/10.1080/23789689.2019.1607658, 2019.

Nan, C. and Sansavini, G.: A quantitative method for assessing resilience of interdependent infrastructures, Reliabil. Eng. Syst. Safe., 157, 35-53, https://doi.org/10.1016/j.ress.2016.08.013, 2017.

Ness, B., Urbel-Piirsalu, E., Anderberg, S., Olsson, L.: Categorising tools for sustainability assessment, Ecol. Econ., 60, 498-508, https://doi.org/10.1016/j.ecolecon.2006.07.023, 2007.

Nex, F., Duarte, D., Steenbeek, A., and Kerle, N.: Towards real-time building damage mapping with low-cost UAV solutions, Remote Sens., 11, 287, https://doi.org/10.3390/rs11030287, 2019.

Nicolas, C., Koks, E., Potter van Loon, A., Arderne, C., Zorn, C., and Hallegatte, S.: Global Power Sector Exposure and Risk Assessment to Natural Disasters, Background paper for this report, World Bank, Washington, D.C., 2019. 
O'Brien, K.: Global environmental change II: from adaptation to deliberate transformation, Prog. Human Geogr., 36, 667-676, https://doi.org/10.1177/0309132511425767, 2012.

OECD: Towards a Framework for the Governance of Infrastructure, Public Governance and Territorial Development Directorate, Paris, 2015.

Oppenheimer, M., Campos, M., Warren, R., Birkmann, J., Luber, G., O’Neill, B., and Takahashi, K.: Emergent risks and key vulnerabilities, in: Climate Change 2014: Impacts, Adaptation, and Vulnerability, Part A: Global and Sectoral Aspects, Cambridge Univ. Press, Cambridge, UK, 1039-1099, 2014.

Ouyang, M.: A mathematical framework to optimize resilience of interdependent critical infrastructure systems under spatially localized attacks, Eur. J. Operat. Res., 262, 1072-1084, https://doi.org/10.1016/j.ejor.2017.04.022, 2017.

Oxman, R.: Performance-based design: current practices and research issues, Int. J. Architect. Comput., 6, 1-17, https://doi.org/10.1260/147807708784640090, 2008.

Panteli, M., Mancarella, P., Trakas, D. N., Kyriakides, E., and Hatziargyriou, N. D.: Metrics and quantification of operational and infrastructure resilience in power systems, IEEE Trans. Power Syst., 32, 4732-4742, https://doi.org/10.1109/TPWRS.2017.2664141, 2017.

Patriarca, R., Bergström, J., Di Gravio, G., and Costantino, F.: Resilience engineering: Current status of the research and future challenges, Safe. Sci., 102, 79-100, https://doi.org/10.1016/j.ssci.2017.10.005, 2018.

Paul, S. and Rather, Z. H.: Quantification of Wind Farm Operational and Infrastructure Resilience, in: 2018 IEEE PES Innovative Smart Grid Technologies Conference Europe (ISGT-Europe), 21-25 October 2018, Sarajevo, Bosnia and Herzegovina, 1-5, https://doi.org/10.1109/ISGTEurope.2018.8571597, 2018.

Pearson, J., Punzo, G., Mayfield, M., Brighty, G., Parsons, A., Collins, P., Jeavons, S., and Tagg, A.: Flood resilience: consolidating knowledge between and within critical infrastructure sectors, Environ. Syst. Decis., 38, 318-329, https://doi.org/10.1007/s10669-018-9709-2, 2018.

Peters, D. P., Pielke, R. A., Bestelmeyer, B. T., Allen, C. D., Munson-McGee, S., and Havstad, K. M.: Cross-scale interactions, nonlinearities, and forecasting catastrophic events, P. Natl. Acad. Sci. USA, 101, 15130-15135, https://doi.org/10.1073/pnas.0403822101, 2004.

Rak, J., Hutchison, D., Calle, E., Gomes, T., Gunkel, M., Smith, P., Tapolcai, J., Verbrugge, S., and Wosinska, L.: RECODIS: Resilient communication services protecting end-user applications from disaster-based failures, in: 18th International Conference on Transparent Optical Networks (ICTON), 10-14 July 2016, Trento, Italy, 1-4, https://doi.org/10.1109/ICTON.2016.7550596, 2016.

Ramsey, M. M., Muñoz-Erickson, T. A., Mélendez-Ackerman, E., Nytch, C. J., Branoff, B. L., and Carrasquillo-Medrano, D.: Overcoming barriers to knowledge integration for urban resilience: A knowledge systems analysis of two-flood prone communities in San Juan, Puerto Rico, Environ. Sci. Policy, 99, 48-57, https://doi.org/10.1016/j.envsci.2019.04.013, 2019.

Reed, D., Wang, S., Kapur, K., and Zheng, C.: Systemsbased approach to interdependent electric power delivery and telecommunications infrastructure resilience subject to weather-related hazards, J. Struct. Eng., 142, C4015011, https://doi.org/10.1061/(ASCE)ST.1943-541X.0001395, 2015.

Restemeyer, B., van den Brink, M., and Woltjer, J.: Between adaptability and the urge to control: making long-term water policies in the Netherlands, J. Environ. Plan. Manage., 60, 920-940, https://doi.org/10.1080/09640568.2016.1189403, 2017.

Rinaldi, S. M., Peerenboom, J. P., and Kelly, T. K.: Identifying, understanding, and analyzing critical infrastructure interdependencies, IEEE Control Syst. Mag., 21, 11-25, https://doi.org/10.1109/37.969131, 2001.

Rodriguez, A. A., Cifdaloz, O., Anderies, J. M., Janssen, M. A., and Dickeson, J.: Confronting management challenges in highly uncertain natural resource systems: a robustnessvulnerability trade-off approach, Environ. Model. Assess., 16, 15-36, https://doi.org/10.1007/s10666-010-9229-z, 2011.

Román-De La Sancha, A., Mayoral, J. M., Hutchinson, T. C., Candia, G., Montgomery, J., and Tepalcapa, S.: Assessment of fragility models based on the Sept 19th, 2017 earthquake observed damage, Soil Dynam. Earthq. Eng., 125, 105707, https://doi.org/10.1016/j.soildyn.2019.105707, 2019.

Roy, K. C., Cebrian, M., and Hasan, S.: Quantifying human mobility resilience to extreme events using geo-located social media data, EPJ Data Sci., 8, 18, https://doi.org/10.1140/epjds/s13688019-0196-6, 2019.

Rozenberg, J. and Fay, M.: Beyond the gap: How countries can afford the infrastructure they need while protecting the planet The World Bank, Washington, DC, https://doi.org/10.1596/9781-4648-1363-4, 2019.

Ruijters, E. and Stoelinga, M.: Fault tree analysis: A survey of the state-of-the-art in modeling, analysis and tools, Comput. Sci. Rev., 15, 29-62, https://doi.org/10.1016/j.cosrev.2015.03.001, 2015.

Ruijters, E. and Stoelinga, M.: Better railway engineering through statistical model checking, in: International Symposium on Leveraging Applications of Formal Methods, Springer, Cham, 151-165, https://doi.org/10.1007/978-3-319-47166-2_10, 2016.

Salinas Rodriguez, C. N., Ashley, R., Gersonius, B., Rijke, J., Pathirana, A., and Zevenbergen, C.: Incorporation and application of resilience in the context of water-sensitive urban design: linking European and Australian perspectives, Wiley Interdisciplin. Rev.: Water, 1, 173-186, https://doi.org/10.1002/wat2.1017, 2014.

Sapkota, R. P., Stahl, P. D., and Rijal, K.: Restoration governance: An integrated approach towards sustainably restoring degraded ecosystems, Environ. Dev., 27, 83-94, https://doi.org/10.1016/j.envdev.2018.07.001, 2018.

Scheffer, M., Carpenter, S., Foley, J. A., Folke, C., and Walker, B.: Catastrophic shifts in ecosystems, Nature, 413, 6856, https://doi.org/10.1038/35098000, 2001.

Schippers, M. C., Edmondson, A. C., and West, M. A.: Team reflexivity as an antidote to team informationprocessing failures, Small Group Res., 45, 731-769, https://doi.org/10.1177/1046496414553473, 2014.

Sharma, N., Tabandeh, A., and Gardoni, P.: Resilience analysis: a mathematical formulation to model resilience of engineering systems, Taylor \& Francis, UK, https://doi.org/10.1080/23789689.2017.1345257, 2017.

Sheykhmousa, M., Kerle, N., Kuffer, M., and Ghaffarian, S.: Post-disaster recovery assessment with machine learning-derived 
land cover and land use information, Remote Sens., 11, 1174, https://doi.org/10.3390/rs11101174, 2019.

Shittu, E., Parker, G., and Mock, N.: Improving communication resilience for effective disaster relief operations, Environ. Syst. Decis., 38, 379-397, https://doi.org/10.1007/s10669-018-96945, 2018.

Shrier, D., Wu, W., and Pentland, A.: Blockchain and infrastructure (identity, data security), Massachusetts Institute of Technology Connection Science, Massachusetts, 1, 1-19, 2016.

Siegel, A. W. and Schraagen, J. M. C.: Measuring workload weak resilience signals at a rail control post, IIE T. Occupat. Ergonom. Human Fact., 2, 179-193, https://doi.org/10.1080/21577323.2014.958632, 2014.

Siegel, A. W. and Schraagen, J. M. C.: Beyond procedures: Team reflection in a rail control centre to enhance resilience, Safe. Sci., 91, 181-191, https://doi.org/10.1016/j.ssci.2016.08.013, 2017a.

Siegel, A. W. and Schraagen, J. M. C.: Team reflection makes resilience-related knowledge explicit through collaborative sensemaking: observation study at a rail post, Cognit. Technol. Work, 19, 127-142, https://doi.org/10.1007/s10111-016-0400-4, $2017 b$.

Spence, S. M. and Kareem, A.: Performance-based design and optimization of uncertain wind-excited dynamic building systems, Eng. Struct., 78, 133-144, https://doi.org/10.1016/j.engstruct.2014.07.026, 2014.

Sridharan, V., Broad, O., Shivakumar, A., Howells, M., Boehlert, B., Groves, D. G., Rogner, H. H., Taliotis, C., Neumann, J. E., Strzepek, K. M., and Lempert, R.: Resilience of the Eastern African electricity sector to climate driven changes in hydropower generation, Nat. Commun., 10, 302, https://doi.org/10.1038/s41467-018-08275-7, 2019.

Staddon, C., Ward, S., De Vito, L., Zuniga-Teran, A., Gerlak, A. K., Schoeman, Y., Hart, A., and Booth, G.: Contributions of green infrastructure to enhancing urban resilience, Environ. Syst. Decis., 38, 330-338, https://doi.org/10.1007/s10669-018-9702-9, 2018.

Steen, R. and Aven, T.: A risk perspective suitable for resilience engineering, Safe. Sci., 49, 292-297, https://doi.org/10.1016/j.ssci.2010.09.003, 2011.

Stern, M. J. and Baird, T. D.: Trust ecology and the resilience of natural resource management institutions, Ecol. Soc., 20, 14, https://doi.org/10.5751/ES-07248-200214, 2015.

Stive, M. J., de Schipper, M. A., Luijendijk, A. P., Aarninkhof, S. G., van Gelder-Maas, C., van Thiel de Vries, J. S., de Vries, S., Henriquez, M., Marx, S., and Ranasinghe, R.: A new alternative to saving our beaches from sea-level rise: The sand engine, J. Coast. Res., 29, 1001-1008, https://doi.org/10.2112/JCOASTRES-D13-00070.1, 2013.

Thacker, S., Pant, R., and Hall, J. W.: System-of-systems formulation and disruption analysis for multi-scale critical national infrastructures, Reliabil. Eng. Syst. Safe., 167, 30-41, https://doi.org/10.1016/j.ress.2017.04.023, 2017.

Troccoli, A., Dubus, L., and Haupt, S. E.: Weather matters for energy, Springer, Berlin, https://doi.org/10.1007/978-1-4614-92214, 2014.

Tsavdaroglou, M., Al-Jibouri, S. H., Bles, T., and Halman, J. I.: Proposed methodology for risk analysis of interdependent critical infrastructures to extreme weather events, Int. J. Crit. Infrastruct. Protect., 21, 57-71, https://doi.org/10.1016/j.ijcip.2018.04.002, 2018.
Underwood, P. and Waterson, P.: Systemic accident analysis: examining the gap between research and practice, Accident Anal. Prevent., 55, 154-164, https://doi.org/10.1016/j.aap.2013.02.041, 2013.

Van der Bijl-Brouwer, M. and Dorst, K.: Advancing the strategic impact of human-centred design, Design Stud., 53, 1-23, https://doi.org/10.1016/j.destud.2017.06.003, 2017.

Van den Beukel, A. P. and van der Voort, M. C.: How to assess driver's interaction with partially automated driving systems A framework for early concept assessment, Appl. Ergonom., 59, 302-312, https://doi.org/10.1016/j.apergo.2016.09.005, 2017.

Venkataramanan, V., Packman, A. I., Peters, D. R., Lopez, D., McCuskey, D. J., McDonald, R. I., Miller, W. M., and Young, S. L.: A systematic review of the human health and social well-being outcomes of green infrastructure for stormwater and flood management, J. Environ. Manage., 246, 868-880, https://doi.org/10.1016/j.jenvman.2019.05.028, 2019.

Vuik, V., Jonkman, S. N., Borsje, B. W., and Suzuki, T.: Naturebased flood protection: The efficiency of vegetated foreshores for reducing wave loads on coastal dikes, Coast. Eng., 116, 42-56, https://doi.org/10.1016/j.coastaleng.2016.06.001, 2016.

Vuik, V., Borsje, B. W., Willemsen, P. W., and Jonkman, S. N.: Salt marshes for flood risk reduction: Quantifying long-term effectiveness and life-cycle costs, Ocean. Coast. Manage., 171, 96110, https://doi.org/10.1016/j.ocecoaman.2019.01.010, 2019.

Walker, B., Holling, C. S., Carpenter, S., and Kinzig, A.: Resilience, adaptability and transformability in social-ecological systems, Ecol. Soc., 9, 5, 2004.

Walker, B., Carpenter, S., Anderies, J., Abel, N., Cumming, G., Janssen, M., Lebel, L., Norberg, J., Peterson, G., and Pritchard, R.: Resilience management in social-ecological systems: A working hypothesis for a participatory approach, Ecol. Soc., 6, 14, 2018.

Wamsler, C.: Cities, Disaster Risk and Adaptation, in: Routledge Critical Introductions to Urbanism and the City, Routledge, London, 2014.

Wang, W., Yang, S., Stanley, H. E., and Gao, J.: Local floods induce large-scale abrupt failures of road networks, Nat. Commun., 10, 2114, https://doi.org/10.1038/s41467-019-10063-w, 2019.

Wardekker, J. A., de Jong, A., Knoop, J. M., and van er Sluijs, J. P.: Operationalising a resilience approach to adapting an urban delta to uncertain climate changes, Technol. Forecast. Social Change, 77, 987-998, https://doi.org/10.1016/j.techfore.2009.11.005, 2010.

Wei, H. H., Sim, T., and Han, Z.: Confidence in authorities, neighbourhood cohesion and natural hazards preparedness in Taiwan, Int. J. Disast. Risk Reduct., 40, 101265 , https://doi.org/10.1016/j.ijdrr.2019.101265, 2019.

Wolch, J. R., Byrne, J., and Newell, J. P.: Urban green space, public health, and environmental justice: The challenge of making cities 'just green enough', Landsc. Urban Plan., 125, 234-244, https://doi.org/10.1016/j.landurbplan.2014.01.017, 2014.

Woods, D. D.: Four concepts for resilience and the implications for the future of resilience engineering, Reliabil. Eng. Syst. Safe., 141, 5-9, https://doi.org/10.1016/j.ress.2015.03.018, 2015.

$\mathrm{Wu}, \mathrm{J}$. and $\mathrm{Wu}, \mathrm{T}$. : Ecological resilience as a foundation for urban design and sustainability, In Resilience in Ecology and Urban Design, Springer, Dordrecht, 211-229, https://doi.org/10.1007/978-94-007-5341-9_10, 2013. 
Wu, Y., Tornatore, M., Martel, C. U., and Mukherjee, B.: Content Fragmentation: A Redundancy Scheme to Save Energy in Cloud Networks, IEEE T. Green Commun. Netw., 2, 1186-1196, https://doi.org/10.1109/TGCN.2018.2870616, 2018.

WWAP - United Nations World Water Assessment Programme: The United Nations World Water Development Report 2018: Nature-Based Solutions for Water, UNESCO, Paris, 2018.

Xue, X., Wang, L., and Yang, R. J.: Exploring the science of resilience: critical review and bibliometric analysis, Nat. Hazards, 90, 477-510, https://doi.org/10.1007/s11069-017-3040-y, 2018.
Zhang, X., Mahadevan, S., Sankararaman, S., and Goebel, K.: Resilience-based network design under uncertainty, Reliabil. Eng. Syst. Safe., 169, 364-379, https://doi.org/10.1016/j.ress.2017.09.009, 2018.

Zimmerman, R., Zhu, Q., and Dimitri, C.: Promoting resilience for food, energy, and water interdependencies, J. Environ. Stud. Sci., 6, 50-61, https://doi.org/10.1007/s13412-016-0362-0, 2016.

Zou, Q. and Chen, S.: Enhancing resilience of interdependent traffic-electric power system, Reliabil. Eng. Syst. Safe., 191, 106557, https://doi.org/10.1016/j.ress.2019.106557, 2019. 